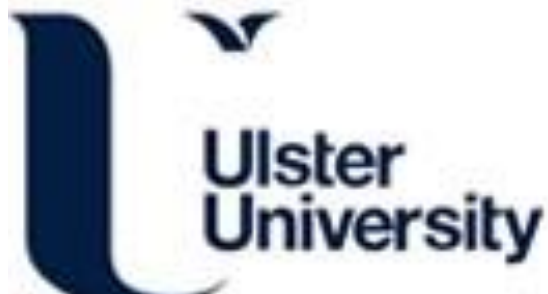

\section{Using simulation-based system dynamics and genetic algorithms to reduce the cash flow bullwhip in the supply chain}

Badakhshan, E., Humphreys, P., Maguire, L., \& Mclvor, R. (2020). Using simulation-based system dynamics and genetic algorithms to reduce the cash flow bullwhip in the supply chain. International Journal of Production Research, 58(17), 5253-5279. https://doi.org/10.1080/00207543.2020.1715505

Link to publication record in Ulster University Research Portal

\section{Published in:}

International Journal of Production Research

Publication Status:

Published (in print/issue): 01/09/2020

DOI:

10.1080/00207543.2020.1715505

\section{Document Version}

Author Accepted version

\section{General rights}

Copyright for the publications made accessible via Ulster University's Research Portal is retained by the author(s) and / or other copyright owners and it is a condition of accessing these publications that users recognise and abide by the legal requirements associated with these rights.

\section{Take down policy}

The Research Portal is Ulster University's institutional repository that provides access to Ulster's research outputs. Every effort has been made to ensure that content in the Research Portal does not infringe any person's rights, or applicable UK laws. If you discover content in the Research Portal that you believe breaches copyright or violates any law, please contact pure-support@ulster.ac.uk. 


\section{N T E R N A T I O NAL JOUR N A L O F}
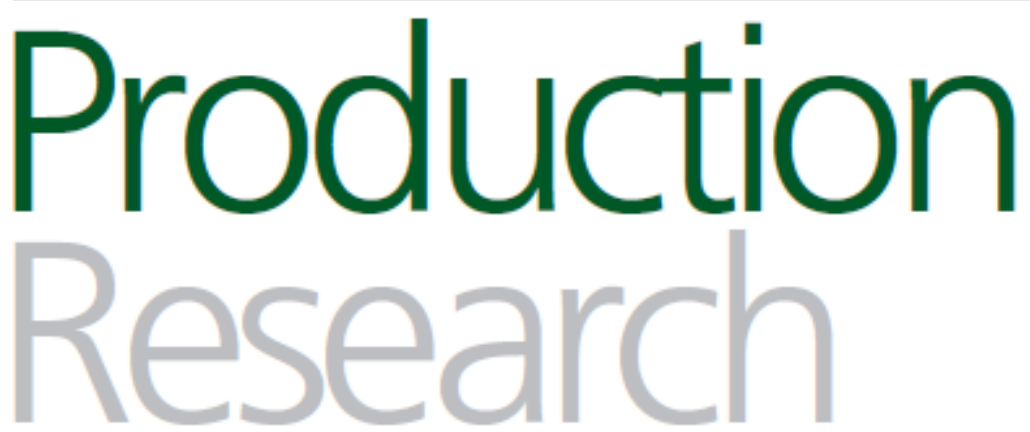

Official Joumal of the International Foundation for Production Research

\section{Editor-in-Chief: Alexandre Dolgui}




\section{Using simulation-based system dynamics and genetic algorithms to reduce the cash flow bullwhip in the supply chain}

\begin{tabular}{|c|c|}
\hline Journal: & International Journal of Production Research \\
\hline Manuscript ID & TPRS-2019-IJPR-0875.R2 \\
\hline Manuscript Type: & Original Manuscript \\
\hline $\begin{array}{r}\text { Date Submitted by the } \\
\text { Author: }\end{array}$ & 10-Dec-2019 \\
\hline Complete List of Authors: & $\begin{array}{l}\text { Badakhshan, Ehsan; Ulster University } \\
\text { Humphreys, P; University of Ulster, Faculty of Business and } \\
\text { Management; } \\
\text { Maguire, Liam; University of Ulster, Engineering } \\
\text { McIvor, Ronan; Ulster University Business School }\end{array}$ \\
\hline Keywords: & SIMULATION, SUPPLY CHAIN MANAGEMENT, ARTIFICIAL INTELLIGENCE \\
\hline Keywords (user): & \\
\hline
\end{tabular}

\section{SCHOLARONE ${ }^{\text {m }}$ Manuscripts}




\title{
Using simulation-based system dynamics and genetic algorithms to reduce the cash flow bullwhip in the supply chain
}

\author{
Ehsan Badakhshan \\ Badakhshan-E@ulster.ac.uk \\ Ulster University, Derry, BT48 7JL, Northern Ireland \\ Paul Humphreys \\ Pk.humphreys@ulster.ac.uk \\ Ulster University, Jordanstown, BT37 0QB, Northern Ireland \\ Liam Maguire \\ Lp.maguire@ulster.ac.uk \\ Ulster University, Derry, BT48 7JL, Northern Ireland \\ ${ }^{1}$ Ronan McIvor \\ R.mcivor@ulster.ac.uk \\ Ulster University, Jordanstown, BT37 0QB, Northern Ireland \\ 02895367257 \\ ${ }^{1}$ Corresponding author
}




\section{Keywords}

Supply chain management; artificial intelligence; simulation; genetic algorithms and the bullwhip effect. 


\section{Minimizing the cash flow bullwhip effect in a supply chain using simulation-based genetic algorithms optimization}

\section{Introduction}

Supply chain management (SCM) refers to the coordination of various processes, such as inventory management and pricing, amongst the members in order to make a trade-off between responsiveness and efficiency for the market being served (Hugos 2011). To remain responsive to uncertain demand conditions, firms carry inventory to prevent orders being lost and also try to update orders placed to their upstream member according to the volatility in demand of their downstream member. However, there is a delay between the order placement time and the receiving of the order by the upstream member. In other words, the volatility in demand is not concurrently perceived by the upstream members such as the manufacturer and distributor. This unwanted phenomenon is called the Bullwhip Effect (BWE) and is mostly attributed to the lack of coordination between participants, distorted information, and information delays in the supply chain (Coppini et al. 2010).

Cash flow management plays a critical role in supply chain management, as firms require cash to implement operational decisions such as holding inventory and capacity expansion in order to improve responsiveness. Cash for each supply chain member is replenished by receiving cash from the downstream member and depleted by payment to upstream members. The inability of a supply chain entity to manage cash effectively, not only curbs its ability to implement operational decisions which reduces the level of service to its downstream members, but also negatively affects the flow of cash that is transferred to its upstream member. Therefore, it is imperative that supply chain members have access to cash at the right time.

In addition to the inefficiencies in product flow within a supply chain, such as excessive inventory, stock-outs, distorted demand forecasting (Chen et al. 2000; Lee, Padmanabhan, and Whang 1997), the BWE also negatively affects the financial flow through heterogonous distribution of cash among supply chain members. The cash conversion cycle (CCC) is one of the pivotal metrics used to measure supply chain efficiency in cash flow management (Zhao et al. 2015). The CCC is defined as the length of time that it takes for a company to convert resource inputs into cash flows collected from customers (Stewart 1995). The lower the CCC, the more successful the firm is in managing cash flow. For example, Amazon is a role model in the effective management of cash flow possessing a CCC of -51 days in 2009 (Kumar, Eidem, and Perdomo 2012). Indeed, Amazon collects cash from customers before providing any service. Reducing the number of days inventory held at a firm is one of the actions that can be taken to reduce the CCC (Randall and Theodore Farris 2009). Volatility in inventory levels, which is caused by the BWE, results in variability in the number of days inventory outstanding, and accordingly causes variations in the CCC (Tangsucheeva and Prabhu 2013). In such circumstances, supply chain members may face liquidity constraints, as they are not able to predict the amount of time that it takes to get access to the cash. The term "cash flow bullwhip" (CFB) was first introduced by Tangsucheeva and Prabhu (2013) to name this undesirable phenomenon, which is caused by variations in the CCC that occurs throughout financial flows in the supply chain. 
Simulation models have been widely applied to supply chain modelling, owing to their capability in capturing complexities and incorporating the dynamic behaviour of supply chains (Kleijnen 2005). System dynamics (SD) is a simulation approach which captures the dynamic behaviour of the system through considering information feedbacks and delays in the model (Mula et al. 2013). This approach was applied for modelling the BWE in supply chains (Wangphanich, Kara, and Kayis 2010; Adenso-Díaz et al. 2012). SD modelling has provided significant insights into the dynamic behaviour of supply chains, however it is not able to determine the optimal values for the decision variables. Incorporating an optimization algorithm into a SD simulation model is likely to yield optimal decisions (Aslam 2013). Such a consolidated framework is called simulation-based optimization (SBO). Therefore, in this study, an SBO framework including genetic algorithm (GA) and SD is applied to determine the optimal values to the inventory and financial decisions so as to minimize the CFB, BWE, and supply chain total cost.

Although, the SBO methodology has been applied for BWE reduction, it has not been applied for CFB minimization. Aslam and $\mathrm{Ng}$ (2016) used the SBO methodology to determine the optimal values to the inventory and supply line forecasting parameters in order to minimize inventory cost, backlog cost, and BWE of the entire supply chain. This study minimizes the CFB, the BWE, and the total cost of the supply chain through recognizing optimal values for the unit cost and price parameters in addition to the inventory and supply line forecasting parameters.

The rest of the paper is organised as follows: the literature review is presented in section 2. Modelling of the CFB in a multi-stage supply chain network and the proposed SBO framework are described in section 3. Section 4 discusses integrated modelling of the cash and material flows in the Beer distribution game. Managerial implications, limitations of the study and further research directions are presented in section 5.

\section{Literature review}

\subsection{The bullwhip effect and cash flow bullwhip}

Several studies have investigated the BWE (Lin et al. 2014; Ma and Ma 2017). The origin of this phenomenon comes from system dynamics theory developed by Forrester (1997), where, in many cases, there was a huge discrepancy between the variance of the perceived demand for a manufacturer and end customer demand. In addition, it was identified that this high positive discrepancy occurred at each stage in the supply chain. The simplest form of the BWE was shown by Sterman (1989) through the "Beer Distribution Game" that considered the impact of human bounded rationality and also time delays on the dynamic system of supply chain. Five main causes of the bullwhip effect were identified as: demand forecasting; order batching; rationing and shortage gaming; price fluctuation; and lead time (Lee, Padmanabhan, and Whang 1997). Several techniques such as reducing time delays or redesigning the supply chain network have been proposed to reduce the bullwhip effect through decreasing the degree of uncertainty and variability that exist in the supply system (Gangopadhyay and Huang 2002; De La Fuente and Lozano 2007; Chatfield 2013).

Chen et al. (2000) quantified the bullwhip effect by obtaining the ratio between the variance of orders and the variance of demand. Dudas, Hedenstierna, and $\mathrm{Ng}$ (2011) proposed the highest order value as a metric for measuring the BWE. Geary, Disney, and Towill (2006) 
classified adopted approaches for measuring the BWE into: (1) Operational research and statistical approach ,e.g., (Chen et al. 2000), (2) engineering of control systems ,e.g., (Hassanzadeh, Jafarian, and Amiri 2014), and (3) simulation, e.g., (Ma and Ma 2017),

Dolgui et al. (2019) showed that the ripple effect, which is related to the structural dynamics in the supply chain can be a driver of the BWE. They proposed a contingent production-inventory control policy to mitigate both ripple and bullwhip effects. Alongside this work Ivanov (2017) argues that the potential of applying simulation modelling to the ripple effect remains under-explored. Ivanov (2018) also identifies the sustainability factors, which either diminish or expand the ripple effect using simulation modelling of a multi-stage supply chain. Ivanov (2019) applied discrete-event simulation to investigate the interrelations of structural vulnerability including the ripple effect, operational vulnerability and the BWE. The results indicate the need for simultaneous consideration of structural and operational vulnerabilities in supply chain management.

Tangsucheeva and Prabhu (2013) quantified the CFB as the ratio of variability in $\mathrm{CCC}$ to variability in the end customer demand. The BWE and lead time were identified as the most significant contributors to the CFB in an inventory system with the order up to (OUT) replenishment policy. Goodarzi et al. (2017) integrated system dynamics (SD) and response surface methodology (RSM) to identify the most important causes of the CFB amongst the lead time, demand forecast updating, and rationing and shortage gaming in centralized and decentralized supply chains. They identified rationing and shortage gaming as the main cause of CFB in inventory systems with OUT policy, while it was identified as the least significant contributor to CFB in Tangsucheeva and Prabhu (2013) study.

Some studies investigated cash flow risks within supply chain networks. For instance, Zhao et al. (2015) studied the cash flow risks in a dual-channel supply chain, in which a manufacturer offers a consignment sales contract to the retailer. Applying demand forecasting techniques and sharing end customer demand information within the network are recommended as ways to reduce demand uncertainty and cash flow risks. Tsai (2008) presented a simulation model to show common solutions for improving CCC such as offering early payment discounts, increasing cash flow risks which were measured by the standard deviations of cash inflows in a planning horizon. C.-Y. Tsai (2017) show how inventory reduction strategies such as just-in-time can lower cash flow risks through shrinking days in inventory.

Previous research on the BWE has highlighted the existence of the phenomenon, and suggested policies such as information sharing to mitigate its adverse effects. However, the aim of the research in this paper is to minimize the BWE by finding the optimal values to the controllable decisions of the supply chain members without implementing a corrective policy. Moreover, there is a lack of research, which incorporates cash flow modelling into the system dynamics simulation of the BWE.

Much of the previous research on the CFB has identified the causes of the phenomenon. There is a lack of studies that focus on minimizing the CFB through finding the optimal values to the desired inventory, the desired supply line, the demand forecast updating parameter $(\alpha)$, and the rationing and shortage gaming parameter $(\beta)$ which lead to the inventory bullwhip. Furthermore, price and unit cost are two decision parameters that assist the decision maker in controlling variations in the CCC. This study minimizes the CFB 
through identifying the optimal values for price, unit cost, and inventory decisions that cause the inventory bullwhip.

\subsection{Simulation-based optimization (SBO) for the supply chain}

Studies have been conducted on applying a SBO approach for modelling supply chain networks can be categorized in terms of their simulation approach. Theme 1, as shown in Table 1, corresponds to the studies in which SD was applied as simulation technique. For instance, O'Donnell et al. (2006) presented an SBO framework which minimized the BWE through identifying optimal order quantities for supply chain members. Georgiadis and Athanasiou (2013) integrated SD and an optimum-seeking search procedure to determine the optimal capacity planning decisions so as to maximize the profit of a SC network. Aslam and $\mathrm{Ng}$ (2016) consolidated SD and multi-objective optimization (MOO) to study the "Beer Distribution Game". The main objective of their model was to find the optimal values of desired inventory, desired supply line, forecasting parameter for inventory, and forecasting parameter for supply line for supply chain entities to make trade-offs between supply chain inventory cost, backlog cost, and the BWE. Sudarto, Takahashi, and Morikawa (2017) developed the SBO model presented by (Georgiadis and Athanasiou 2013) through considering social and environmental sustainability. A simplified non-linear multi-objective algorithm was applied to determine the optimal values for capacity planning decisions.

The second group of papers used DES for simulation modelling. For instance, Ding, Benyoucef, and Xie (2009) present a simulation-based optimization model which incorporates multi-objective genetic algorithm (MOGA) and discrete-event simulation (DES) models. The proposed model was applied through a case study from automotive industry and provided both optimal configuration decisions and operation strategies in order to make a trade-off between customer service level and total cost of the supply chain. Bandaly, Satir, and Shanker (2016) coupled DES and GA to determine optimal safety stock level and financial options to place in order to minimize the expected total opportunity cost of a threeechelon beer supply chain. Keramydas et al. (2017) integrated the DES and OptQuest to determine the optimal stock levels and SC network design so as to minimize $\mathrm{CO} 2$ emissions and the total cost of the SC.

The third category contains studies which applied agent-based simulation. Mele et al. (2006) developed an SBO framework to address demand uncertainty in chemical supply chains. The proposed model includes an agent-based simulation model which is paired with a Genetic Algorithm (GA) to determine optimal operative parameters of supply chain members. Nikolopoulou and Ierapetritou (2012) coupled MILP and agent-based simulation to minimize total cost of a SC network by recognising the optimal operational decisions such as production planning decisions. Peirleitner, Altendorfer, and Felberbauer (2016) integrated a Non-dominated Sorting Genetic Algorithm (NSGA-II) and an Agent-based simulation model to recognise optimal inventory policies for supply chain members under demand and replenishment lead time uncertainties. The objective of the model was to determine an optimal reorder point and order quantity of Stock Keeping Units (SKUs) for entities in a general supply chain network so as to minimize the total supply chain cost, while maximizing service level for retailers.

Finally, theme 4 includes the studies in which other simulation approaches except for the three aforementioned techniques, i.e., SD, DES, and agent-based simulation, were 
applied. Puigjaner and Laínez (2008) used a SBO approach to find optimal values of design, planning, and financial decisions in order to maximize corporate value which was measured by the discounted-free-cash-flow method. Gao and Wang (2008) claim that analytical models are not able to represent clearly some stochastic variables such as stochastic demand. They developed an SBO model that combined simulation and particle swarm optimization (PSO) algorithm to determine optimal inventory policies including reorder points and economic order quantities of members in a three-echelon supply chain under demand uncertainty. Diaz, Bailey, and Kumar (2016) proposed a discrete Markov-modulated demand which is integrated with an optimization algorithm, combining simulated annealing, pattern search, and ranking and selection (SAPS\&RS) to determine optimal values of $(\mathrm{s}, \mathrm{S})$ inventory decisions in order to minimize total inventory cost. Boulaksil (2016) developed an SBO model to recognize safety stock levels in supply chain systems under demand uncertainty.

As presented in Table 1, most researchers applied SBO approach to model product flow within the supply chain. In contrast, integrated modelling of the cash and product flows is only considered in a few works (Puigjaner and Laínez 2008; Bandaly, Satir, and Shanker 2016). Furthermore, much of the literature focuses on reducing the detrimental effects of the BWE in material flow. However, limited research has been undertaken on minimizing the CFB through finding optimal values for the price, unit cost, and inventory and supply line control parameters using SBO modelling based on the replenishment model of Mosekilde et al. (1991). Hence, this paper considers price and unit cost parameters for minimizing CCC variation and CFB. Moreover, $\mathrm{CFB}$ minimization is incorporated into an SBO model as an objective function. Such an approach has not been considered in the SBO literature.

\section{TAKE IN TABLE 1.}

Based on the system dynamics structure of the Beer distribution game, firstly a simulation model for measuring total cost, BWE, and CCC variance is developed. Feasible intervals for model inputs (e.g., inventory and supply line control parameters, price, and unit cost) are then defined and the SBO approach is applied to find optimal values for the input parameters to minimize the BWE, CFB, and total cost of the chain. Hence, a new approach for managing the CFB and its inverse effects is presented. This approach provides supply chain managers with a novel way of controlling CCC variability through recognising optimal combination of physical and cash flows decisions.

\section{The supply chain model for cash flow bullwhip effect}

A supply chain incorporates integrated processes by which products are converted from raw material into finished goods. As these processes are performed by different business functions in diverse companies such as procurement, production and logistics, the various departments of the firms need to collaborate, coordinate, and interact in order to produce the product in the supply chain and deliver it to end customers (Kim et al. 2004). Hence, supply chains can be considered as complex networks that require the modelling of interaction effects between the entities with multiple objectives, which sometimes contradict each other (Keramati 2010). In order to study supply chain networks, analytical approaches such as optimization models have been frequently utilized to provide optimal values to the decision variables for supply chain members (Wu 2006; Torabi and Hassini 2008; Govindan et al. 2014; Hamta et al. 2015). Although pure mathematical models are useful in many cases, they 
may not be able to depict complex relationships, including feedback loops and delay functions, between supply chain entities existing in real-world problems (Mele et al. 2006).

On the other hand, simulation has been proved to be an efficient tool to describe and analyse inherent dynamic behaviour of complex systems such as supply chains (Dominguez, Cannella, and Framinan 2015; Macdonald et al. 2018). Hence, simulation modelling can comprehensively handle dynamics rooted in supply chain problems when the problem may not be easily formulated in the form of analytical models since solving complicated mathematical models is not cost-effective (Wan, Pekny, and Reklaitis 2005). Moreover, simulation models provide the opportunity to examine the consequences of diversified policies by conducting what-if analysis. There are a variety of simulation tools applied to study supply chain issues including Discrete event simulation, Petri nets, Agent-based simulation (Kleijnen 2005). System dynamics (SD) is one of the simulators of the "Beer Distribution Game". Given these discussions, simulation stages of our case study model are outlined as follows.

First, nomenclatures are demonstrated. Second, ordering policies applied by supply chain members are introduced and causes of the inventory bullwhip are identified in the ordering policy. Then, the impact of the ordering policy on CCC is investigated. To measure variations of the $\mathrm{CCC}$ and $\mathrm{CFB}$, the SD simulation model of the studied supply chain composed of one manufacturer, one distributor, one wholesaler, and one retailer is developed. Causes of the inventory bullwhip and CFB are part of inputs and outputs of the simulation model, respectively. The validity of the SD model is assessed through implementing an extreme condition test. Furthermore, the capability of the model in showing the bullwhip effect within the supply chain network is another proof of its validity. Thereafter, feasible intervals of the input parameters, including causes of inventory bullwhip, price, and unit cost, are defined and the SBO approach is applied to derive optimal combination of the parameters to minimize CFB, BWE, and SCTC. Nomenclatures are presented in Table 2.

TAKE IN TABLE 2.

\subsection{Ordering policy}

In this study we have applied the ordering policy developed by Mosekilde et al. (1991) to calculate the amount to order (OP) for each member of the supply chain. The placed order which must be non-negative is calculated as:

$$
\mathrm{OP}_{\mathrm{t}}=\operatorname{MAX}\left(0, \mathrm{DOP}_{\mathrm{t}}\right)
$$

(1)

Where the desired amount to order (DOP) is defined as follows:

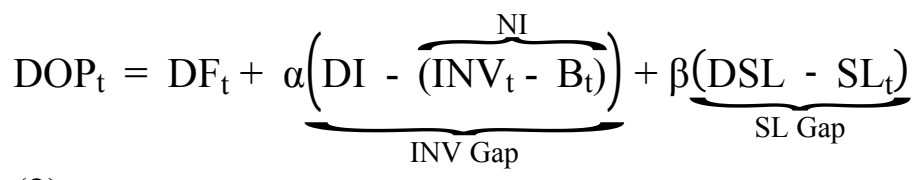

To determine the desired amount to order (DOP), each member endeavours not only to meet the forecasted demand of its downstream member but also bridge the inventory and 
supply line gaps. The exponential smoothing method with a smoothing parameter $(\gamma)$ that equals to one is used to forecast the demand forecast (DF) as follows:

$$
\mathrm{DF}_{\mathrm{t}}=\operatorname{SMOOTH}\left(\mathrm{D}_{\mathrm{t}}, \gamma\right)
$$

The inventory gap is the difference between the desired inventory (DI) and net inventory (NI) which is calculated by subtracting the unfulfilled orders (B) from the inventory (INV). The supply line (SL) gap is defined as the gap between the desired and actual supply line. The supply line represents the previous orders which have been sent by the upstream member but still have not been delivered. The desired inventory and the desired supply line are constant values which are specified by each member and represent the inventory levels which are desired to be held or to be on order for each member. As the inventory and supply line gaps are not replenished entirely in a review period, smoothing replenishment rules should be used to give an appropriate weight (i.e., $\alpha$ and $\beta$ ) to the gap terms (Disney et al. 2007).

$\alpha$ and $\beta$ represent the discrepancy of units needed in the form of on-hand inventory (INV) and the supply line (SL) respectively. A high $\alpha$ value indicates an aggressive policy to bridge the gap between the desired inventory and the current net inventory. In the case of $\beta$, a high value shows that all the orders in the supply line have been considered, when deciding on the amount of orders to be placed with the upstream member.

In Expression (2), desired inventory (DI), desired supply line (DSL), inventory proportional parameter $(\alpha)$, and inventory on order proportional parameter $(\beta)$ which are known as controllable parameters allow us to amend the dynamic behaviour of the supply chain. Indeed, changing these exogenous factors results in a set of ordering patterns ranging from order variance amplification (bullwhip) to dampening (smoothing) (Disney et al. 2007). In the next section, it is explained how Expression (2) may lead to a fluctuation in the CCC known as CFB.

\subsection{Impact of ordering policy on $C C C$ and $C F B$}

To recognise the relationship between the order quantity and CCC, first the measuring procedure of CCC must be elaborated. CCC metric is composed of three factors: (1) days inventory outstanding (DIO), (2) days sales outstanding (DSO), and (3) days payable outstanding (DPO). CCC can be defined as follows (Randall and Theodore Farris 2009):

$$
\begin{aligned}
& \mathrm{CCC}=\frac{\text { Average inventory value }}{\mathrm{COGS} / 365}(\mathrm{DIO})+\frac{\text { Average account receivable }}{\text { Revenue } / 365} \text { (DSO) } \\
& -\frac{\text { Average account payable }}{\mathrm{COGS} / 365}(\mathrm{DPO})
\end{aligned}
$$

To determine DIO, the value of average inventory value which is the product of inventory position (I) and sales price per unit (SP) is divided by the daily cost of goods sold (COGS) that is a product of unit cost (UC) and the average demand (D) divided by 365 . Dividing COGS by 365 assures the expression of DIO in days since both average inventory and COGS are expressed in the currency unit (£). Therefore, DIO can be calculated as:

$$
\mathrm{DIO}=365\left(\frac{\mathrm{SP}}{\mathrm{UC}}\right)\left(\frac{\mathrm{I}}{\mathrm{D}}\right)
$$


The average accounts receivable (AR) can be expressed in terms of demand, backlog (B) and inventory level as follows:

$$
\mathrm{AR}=\operatorname{mmin}(\mathrm{SP}(\mathrm{D}+\mathrm{B}), \mathrm{SPI})
$$

Where $\mathrm{m}$ indicates the collection policy of the firm; $0 \leq \mathrm{m} \leq 1$. It would be equal to 1 if all sales is in the form of credit and would be zero if all value of sales is in the form of advanced payment. Replace Eq. (6) in DSO, obtain

$$
\mathrm{DSO}=\mathrm{m}\left(\frac{\min (\mathrm{SP}(\mathrm{D}+\mathrm{B}), \mathrm{SPI})}{\mathrm{SPD} / 365}\right)=365 \mathrm{~m}\left(\frac{\min (\mathrm{D}+\mathrm{B}, \mathrm{I})}{\mathrm{D}}\right)
$$

The average accounts payable (AP) can be calculated by order quantity (q) and sales price of the upstream member (USP) as follows:

$$
\mathrm{AP}=\mathrm{nUSPq}
$$

Where $0 \leq \mathrm{n} \leq 1$, shows the payment policy of the company. It would be equal to 1 for all credit purchases and zero for all purchases the price must be paid before delivery.

Replace Eq. (8) in DPO, we get

$$
\mathrm{DPO}=\frac{\mathrm{nUSPq}}{\mathrm{UCD} / 365}=365 \mathrm{n}\left(\frac{\mathrm{USP}}{\mathrm{UC}}\right)\left(\frac{\mathrm{q}}{\mathrm{D}}\right)
$$

Given Eq. (4), CCC can be obtained as follows:

$$
\mathrm{CCC}=365\left(\frac{\mathrm{SP}}{\mathrm{UC}}\right)\left(\frac{\mathrm{I}}{\mathrm{D}}\right)+365 \mathrm{~m}\left(\frac{\min (\mathrm{D}+\mathrm{B}, \mathrm{I})}{\mathrm{D}}\right)-365 \mathrm{n}\left(\frac{\mathrm{USP}}{\mathrm{UC}}\right)\left(\frac{\mathrm{q}}{\mathrm{D}}\right)
$$

Considering Eq. (10), the cash conversion cycle for supply chain members is a function of order quantity (q), inventory (I), demand (D), sales price per unit (SP), upstream sales price (USP), and unit cost (UC). Each supply chain member applies the replenishment rule presented in Eq. (1) to determine its order quantity. The variability of CCC is used to measure the cash flow bullwhip (CFB) for supply chain members as follows (Tangsucheeva and Prabhu 2013):

$$
\mathrm{CFB}=\frac{\text { Variance of CCC }}{\text { Variance of downstream demand }}=\frac{\operatorname{VAR}(\mathrm{CCC})}{\operatorname{VAR}(\mathrm{D})}
$$

To decrease CFB, the variability of CCC needs to be diminished through determining the optimal values for the inventory decision parameters (e.g., $\alpha, \beta$, DNI, DSL), sales price per unit (SP), and unit cost (UC). To measure CFB through the supply chain, a system dynamics (SD) structure of the Beer distribution game is developed. In this case, inputs are inventory decisions parameters, price, and unit cost (i.e., control parameters) and outputs are variations of cash to cash cycle and CFB for participants. Simulation models that are developed by the SD approach are considered to be more robust than other types of simulation models, even though there are robustness tests that can be used to test the validity of the model. To show the robustness of our developed simulation model, the extreme condition test (Sterman 2000) is applied. The extreme condition test deals with a test accompanied by a reasonable expected behaviour according to its inputs values (Sterman 2000). e.g., dramatic increase in price of a product results in converging the demand function 
to zero (Sterman 2000). To run the extreme condition test in our developed model, sales price per unit of product which is a model input is increased significantly. As a result, the CCC rises dramatically. Hence, it can be concluded that the behaviour of the model is reasonable.

\subsection{Simulation-based optimization (SBO)}

After simulating the supply chain's cash flow and observing the CFB across the supply chain network, we need to manage its adverse effects through recognizing optimal values for the controllable parameters. As was indicated in the previous section, the CCC is a function of order size which is affected by ordering parameters including demand forecast updating $(\alpha)$, and rationing and shortage gaming $(\beta)$ given in Eq. (2). That is to say, the CCC is influenced by factors that contribute to inventory bullwhip, hence our objective is to minimize CFB by recognising optimal values to the ordering parameters, inventory decisions, price, and unit cost. These are input parameters for the simulation model. Moreover, minimizing supply chain total cost and the BWE are other objective functions that will be taken into account. Here, simulation-based optimization (SBO) is used to determine the optimal decision variables through integrating system dynamics (SD) and a Genetic algorithm (GA). SBO is an emerging field which consolidates simulation analysis by integrating optimization methods into it. In other words, SBO transforms simulation model from a descriptive tool toward a prescriptive method. Regardless of the optimization algorithm used, the process of optimizing an SD model involves four steps: (1) Developing the stock and flow diagram, (2) Selecting control parameters by which performance of the system is adjusted, (3) Specifying the lower and upper bounds of control parameters, and (4) Identifying model variables for optimization. These variables represent the values that need to be optimized (Duggan 2008).

After following these steps, the optimization algorithm can be implemented. In all cases, SBO involves an iterative process between the optimizer and the simulation model, where firstly the optimization algorithm inputs a set of parameter values to the simulation model and the simulation model then outputs performance measurements of the model to the optimizer. The optimization algorithm then compares the performance of the system with the performance produced by previous permutations of the parameters in order to generate a new set of parameter values. This process continues until a stop criterion has been met, such as performing a defined number of evaluations, elapsing a specific amount of time or any userspecified criterion (Syberfeldt 2009). The framework of the SBO approach in this study is shown in Figure 1.

\section{TAKE IN FIGURE 1.}

\subsection{Genetic algorithms (GAs)}

Genetic algorithms (GAs) are computational algorithms inspired by Darwinian evolutionary theory which can be called in short as "survival of the fittest" (Darwin 1859). In GAs it is assumed that fittest solutions survive and their characteristics are transferred from one generation to the next (Zaman, Paul, and Azeem 2012). To optimize SD models using GAs, each solution known as a chromosome is represented by an array of elements, where each position in the array pertains to a possible parameter value. A solution pool named population is formed by a set of chromosomes. The algorithm starts with setting up a population of random possible solutions. Then, the chromosomes are evaluated based on the objective function to obtain the fitness of the solution. A fitness value shows how good each solution is 
in satisfying objective functions. Applying the rule of survival of the fittest, strongest solutions are selected from the population. Subsequently, solutions with higher fitness are combined to produce new solutions by performing a crossover operator. These solutions are known as parent solutions. To ensure maintaining variety in the overall population, new solutions may then be subjected to small variations from parent solutions called a mutation operator. Each population then represents a generation, and the process continues until predefined stopping criteria are met, such as convergence of fitness over generations or reaching the maximum number of generations (Lu et al. 2012).

GAs are well suited for parameter optimization and can also be extended to multiple objective optimization (MOO) (Streichert 2002). Therefore, in this research, a GA is employed to specify optimal values to the control parameters (e.g. $\alpha, \beta, D N I, D S L, S P, U C$ ). The proposed fitness function is defined as the inverse of the SCTC, BWE, and CFB as shown in Eq. (12), where a lower TC, BWE, and CFB results in a higher fitness value. SCTC aggregates inventory holding cost and backlog cost of all the members. The BWE is quantified through the ratio between the variance of orders and the variance of demand (Chen et al. 2000). Finally, the CFB is measured through Eq. (11).

$$
\text { Fitness Function }=\frac{1}{\mathrm{SCTC}+\mathrm{MBWE}+\mathrm{MCFB}}
$$

As the initial population in GA, i.e. solution set, is randomly selected within the solution space and also that the optimization process is stochastic, the exact same results will not be replicated every time. To obtain a wide range of optimal results, the optimal parameter sets are gained by defining various initial population. Thereafter, non-dominated optimal solutions are chosen from generated optimal solutions. Finally, the most ideal solution is selected by the decision maker based on higher level information (Duggan 2008). In this work, MATLAB GA toolbox was used to perform the simulation with the fitness function of Eq. (13) with the restriction set on the ranges of the control parameters (e.g. $\alpha, \beta$, DNI, DSL, SP, UC).

\section{The beer distribution game}

The beer game (BG) is a role-playing simulation game and was originally developed by Sterman (1989). The main objective of the game was to demonstrate the existence of the BWE within supply chain networks. In this paper, the flow of cash within the supply chain network is considered in modelling of the BG, in addition to material and information flows, to show the presence of the CFB.

The studied supply chain model is shown in Figure 2. This model consists of four actors: a retailer, a wholesaler, a distributor, and a manufacturer. As in the case of the original $\mathrm{BG}$, there is no information sharing between the supply chain entities and each entity places orders with its upstream member using the ordering policy outlined in section 3.1. The stock and flow structure of the material flow is shown in Figure 3. Joshi (2000) provides a complete description of the BG stock and flow model. Another relevant variable in this model, in addition to the orders placed to the upstream members, is the supply chain total cost (SCTC) (13), which is calculated by aggregating the total cost of the supply chain members. Total cost (14) for each agent is composed of the inventory holding cost and backlog cost. Inventory holding cost (15) is the product of inventory level and unit holding cost. However, 
the backlog cost (16) is determined by multiplying the backlog level into the unit stock out cost.

\begin{tabular}{|l|l|}
\hline Supply chain total cost $=\mathrm{TC}_{\mathrm{M}}+\mathrm{TC}_{\mathrm{D}}+\mathrm{TC}_{\mathrm{W}}+\mathrm{TC}_{\mathrm{R}}$ & $(13)$ \\
\hline Total cost $=$ Inventory holding cost + backlog cost & $(14)$ \\
\hline Inventory holding cost $=$ Inventory $\times$ unit holding cost & $(15)$ \\
\hline Backlog cost $=$ Backlog $\times$ unit stock out cost & $(16)$ \\
\hline
\end{tabular}

\section{TAKE IN FIGURE 2.}

\section{TAKE IN FIGURE 3.}

The financial stock and flow model is shown in Figure 4. Each member pays for the orders placed to its upstream member, and is paid for the orders received from its downstream member. The variable of interest in this model is the CCC which is determined by Eq. (10). The detailed description of the equations used in the financial stock and flow model is provided in Appendix 1.

\section{TAKE IN FIGURE 4.}

\section{1. $M O O$ of the $B G$}

To determine the optimal decision parameters for the supply chain members, an optimization problem which contains the objective functions and constraints on parameter values should to be formulated. The objective functions for the optimization problem are denoted as (17):

$$
\left\{\begin{array}{c}
\text { Min SCTC }=\operatorname{Min} \mu_{\mathrm{SCTC}}=\sum_{\mathrm{t}=0}^{\mathrm{T}} \frac{\mathrm{SCTC}}{\mathrm{T}} \\
\operatorname{Min} \mathrm{MBWE}=\operatorname{Min}{ }^{\sigma^{2} \mathrm{MPO}} / \sigma_{\mathrm{DD}}^{2} \\
\operatorname{Min} \mathrm{MCFB}=\operatorname{Min} \sigma^{2}{ }_{\mathrm{MCCC}} / \sigma_{\mathrm{DD}}^{2}
\end{array}\right.
$$

Decision variables: $\alpha_{i}, \beta_{i}, D_{i}, D_{S L}, S P_{i}, U_{i}$

Subject to:

$$
\begin{aligned}
& 0 \leq \alpha_{\mathrm{i}} \leq 1,0 \leq \beta_{\mathrm{i}} \leq 1,0 \leq \mathrm{DI}_{\mathrm{i}} \leq 12,0 \leq \mathrm{DSL}_{\mathrm{i}} \leq 15,1 \leq \mathrm{SP}_{\mathrm{i}} \leq 4, \\
& 0.5 \leq \mathrm{UC}_{\mathrm{i}} \leq 3.5
\end{aligned}
$$

The first objective function is related to minimizing the SCTC which is measured by the mean of supply chain total cost over the SBO period. The second objective is to minimize the BWE for the manufacturer which is formulated as the ratio of variation in manufacturer's order to variation in its downstream demand. The third objective function pertains to CFB minimization for the manufacturer quantified by the ratio of variation in the manufacturer's $\mathrm{CCC}$ to variation in its downstream demand. The lower and upper bounds for the decision parameters of entity $i$ (e.g., manufacturer, distributor, wholesaler, and retailer) are defined by Eq. (18). The manufacturer, as the final upstream member of the supply chain, endeavours to manage variations in the order quantity, and cash conversion cycle (CCC) in order to reduce 
the BWE, and CFB respectively. It would be interesting to know whether minimizing the order quantity and $\mathrm{CCC}$ fluctuations for the manufacturer results in volatility reduction in order quantity and CCC for other supply chain members. The premise for this model is that the decision maker aims to minimize SCTC and also minimize the BWE and CFB throughout the supply chain network.

\section{Experiments}

This section outlines the results of the tests conducted on the beer distribution game using the SBO methodology and information sharing, which are two common techniques for bullwhip effect reduction. The SBO aims to minimize the total cost of the supply chain in addition to the BWE and CFB for the manufacturer by obtaining the optimal price, unit cost, and inventory decision parameters for all members. The information sharing strategy involves supply chain members being informed about end customer demand.

\subsection{Experiment 1}

The first experiment was designed to test the performance of the SBO and information sharing under the assumptions of the original beer game, which included deterministic demand and lead times. According to the assumptions of the beer game (BG), customer demand starts by ordering 4 crates of beer during the first four weeks and then suddenly, in week 5 , the customer demand rises to 8 crates per week for the rest of the simulation (Joshi 2000). Aslam and $\mathrm{Ng}$ (2016) provides the initial values for material flow variables and parameters at each entity at $\mathrm{t}=0$. The values for cash flow parameters, unit cost and price, are shown in Table 3. As expected from running the SD-BG model, Figure 5 clearly demonstrates the existence of the BWE. The placed orders by upstream members is several orders of magnitude larger than the end customer demand. The manufacturer placed order (MPO) is 3.4 times more than the end customer demand at week 12. This oscillating effect shows how an increase in the customer demand, from four to eight in week 5 , has resulted in a huge oscillating effect at the final upstream member, manufacturer.

\section{TAKE IN TABLE 3. \\ TAKE IN FIGURE 5.}

The inventory levels for entities is shown in Figure 6 . The inventory level for the manufacturer between weeks 25 and 35 remains at 60 , which is 7.5 times larger than the customer demand.

\section{TAKE IN FIGURE 6.}

The variability of the cash conversion cycle (CCC) for supply chain members is shown in Figure 7. The existence of the BWE results in an increase in inventory levels which subsequently leads to a rise in days inventory outstanding (DIO). An increase in DIO also results in CCC growth. The oscillations in CCC rises significantly as we move toward upstream members of the chain so that CCC for the final entity, manufacturer, ranges from 30 to 500 days. Hence, it can be concluded that the existence of the BWE prolongs the cash to cash cycle for the upstream members.

\section{TAKE IN FIGURE 7.}




\subsubsection{Impact of information sharing}

Considering the assumption that SC members do not share the demand information, each entity forecasts the end customer demand based on the previous orders of its downstream member. Most companies amplify the demand of their downstream member which leads to information distortion throughout the supply chain that is one of the main drivers of the BWE. Information sharing is a mechanism which eliminates information distortion and reduces the BWE through sharing the end customer demand between the SC members (Yu et al .2001).

To illustrate the impact of information sharing on diminishing the BWE, CFB and SCTC, the results of the original SD model in which the demand information are not shared among the SC members are compared with the results obtained from the SD model in which there is information sharing between the entities. According to the results shown in Figure 8(a)-(c), the information sharing among the SC members reduces the variability in the placed orders by the customers, variability in inventory levels of the entities, and variability in cash conversion cycles of the entities. According to the results shown in Figure (5), the placed orders by the SC members in the original SD model has a scale of $0-27$. While, after the information sharing the placed orders by the SC members vary in the range of $[1,12]$ (see Figure 8(a)). According to the results shown in Figure (6), the inventory levels of the SD members in the original SD model has a scale of 0-60. While, after the information sharing the inventory levels of the SC entities vary in the range of $[0,20]$ (see Figure 8(b)). According to the results illustrated in Figure (7), the CCCs of the members has a scale of 30500. Although, after the information sharing the CCCs of the SC entities vary in the range of $[0,27]$ (see Figure 8(c)).

As explained, the DIO volatility is caused by increasing the inventory levels. Therefore, mitigating the inventory levels through information sharing reduces the CFB in addition to the BWE. Although the BWE and CFB decrease dramatically as a result of implementing the information sharing strategy, the impact of the strategy on reducing the SCTC is not significant. The SCTC decreases by 8 percent, from $£ 10816$ to $£ 9915.65$. The reason is that the information sharing strategy does not identify the optimal values for the inventory decision parameters which affect the inventory levels of the SC members and consequently the SCTC.

\section{TAKE IN FIGURE 8.}

\subsubsection{SBO implementation}

The execution of the SBO methodology is based on the process referred to in section 3.3. In order to implement the SBO, a number of specific values need to be decided on, including:

- The range of values for decision parameters which are defined by Eq. (18).

- The parameters for the GA which are set as follows: the population size is 200 , the crossover and mutation rates are set to be 0.8 and 0.1 , respectively. To specify an appropriate population size, a number of population sizes are selected and the algorithm is run 15 times for each population size. The results are reported in Table 4. Increasing the population size improves the mean and the standard deviation of the fitness function. The population size of 200 is an appropriate population size as the 
population size of 250 does not improve the best fitness value. However, it slightly reduces the standard deviation of the fitness function.

\section{TAKE IN TABLE 4.}

The optimal solution recommends a non-aggressive strategy toward bridging the gap between the desired inventory and current net inventory, i.e., the value of $\alpha$ for all members is less than 0.5 , and a cautious approach to order quantity for distributor and retailer, i.e., the value of $\beta$ for distributor and retailer is more than 0.5 .

To illustrate the effectiveness of the SBO methodology in minimizing the BWE, CFB, and SCTC, the results of the SBO model in which the end customer demand is not shared among the members are compared with the results obtained from the SD model in which there is information sharing between the entities. According to the results shown in Figure 9 (a), order quantities of all supply chain members converge with customer demand ( 8 crates/week) at week 40. Whilst, before applying the SBO notwithstanding sharing the demand information within the SC network, the placed orders adjust to customer demand at week 60 (see Figure 8(a)). SC members are not required to hold inventory from week 60 until the end of the simulation in the SBO model (see Figure 9(b)), while in the SD model with information sharing at the same period the SC members hold 10 crates/week in inventory (see Figure $8(\mathrm{~b})$ ). Similarly, optimal controllable parameters lead to a 0 day cash conversion cycle for all the members at week 30 (see Figure 9(c)). However, the non-optimal parameter values result in an 11 day cash cycle for the retailer at week 40 (see Figure 8(c)). In addition to the BWE and CFB reduction, implementing the SBO methodology leads to a $29 \%$ decrease in the SCTC due to the lower inventory levels which is held by the SC members. The SCTC reduced from $£ 9915.65$ obtained from the SD model with information to $£ 7017.94$ after employing the SBO methodology.

\section{TAKE IN FIGURE 9.}

\subsection{Experiment 2}

The second experiment examines the performance of the SBO and information sharing under stochastic demand where it is assumed that the customer demand fluctuates in the range of [0,15] (Kimbrough et al. 2002). Figure 10(a) illustrates the ordering quantities for each member of the supply chain before applying the SBO and information sharing. It demonstrates the amplifications occurring in the orders and the customer's orders cannot be easily tracked. The manufacturer placed order (MPO) is 3.4 times more than the highest orders could be placed by the end customer at week 12. As expected the performance of the members in tracking the customer's demand is inferior to their performance in experiment 1. Therefore, the inventory levels of the members that are shown in Figure 10(b) are higher than the inventory levels in experiment 1 (see Figure 6). In experiment 2 before employing the information sharing and SBO, the highest inventory level which held by the SC members is 110 which is held by the distributor at week 30 of the simulation (see Figure 10(b)). While, in experiment 1 the highest inventory level held by the SC members before employing the information sharing and SBO is 60 , which was held by the manufacturer between weeks 25 and 35 (see Figure 6). Figure 10(c) depicts the oscillations in cash cycles of the members, which are higher than the cash cycle oscillations in experiment 1 . The highest CCC for the SC members before information sharing and SBO in experiment 2 is 1432 days. While, the 
highest $\mathrm{CCC}$ for the SC members before information sharing and SBO in experiment 1 is 27 days. The accumulated cost of the supply chain in this experiment before applying BWE reduction techniques is $£ 14283.42$, which is higher than the total cost in experiment 1 .

\section{TAKE IN FIGURE 10.}

\subsubsection{Impact of information sharing}

The impact of information sharing on reducing the BWE, CFB, and SCTC is shown in Figure 11(a)-(c). The ordering quantity of all members is given in Figure 11(a), which has a scale of 0-27. While before information sharing, the placed orders by the SC members has a scale 0 51 (see Figure 10(a)). According to the results shown in Figure 10(b), the inventory levels of the SC members before information sharing has a scale of $0-110$. While, after the information sharing the inventory levels of the SC entities vary in the range of $[0,83]$ (see Figure 11(b)). According to the results illustrated in Figure 10(c), the CCCs of the members before information sharing has a scale of 0-1432. Although, after the information sharing the CCCs of the SC entities vary in the range of $[0,712]$ (see Figure 11(c)). In addition to the BWE and CFB reductions, the SCTC decreased dramatically as a result of implementing the information sharing strategy. The SCTC reduced by 23 percent, from $£ 14283.42$ before information sharing to $£ 10947.54$ after information sharing.

\section{TAKE IN FIGURE 11.}

\subsubsection{Impact of $S B O$}

Using the values for the GA parameters presented in the previous section, the SBO is run for 15 times. The standard deviation of the obtained fitness values is 6.71 and the best fitness value is 8332.83. The order quantities of the members are shown in Figure 12(a), which has a scale of $0-45$. The largest order placed by a member in the SBO method is higher than the largest order placed in the case of information sharing, i.e., 27(see Figure 11(a)). While, the inventory levels of the members, as illustrated in Figure 12(b), are significantly lower than the inventory levels in the information-sharing scenario. The inventory levels of the SC members in the SBO model reaches to 0 at week 30 and remains unchanged until the end of the simulation. While, in the SD model with information sharing the inventory of the retailer who possess the lowest volatility among the SC members fluctuates in the range of $[0,38]$ from week 30 until the end of the simulation (see Figure 11(b)). The cash cycle of the members after using the SBO method is indicated in Figure 12(c) that proves the cash flow bullwhip is significantly reduced comparing the SD model with information sharing. After employing the SBO method, the CCC of the all members remains at 0 day from week 40 until the end of the simulation. While, after employing the information sharing strategy, the CCC of the manufacturer who possess the lowest volatility in cash to cash cycle among the SC members varies in the range of $[0,225]$ (see Figure 11(c)).

The SBO method proposes an aggressive approach toward bridging the gap between the desired inventory and current net inventory for the manufacturer and retailer. This implies that the value of $\alpha$ for the manufacturer and retailer is less than 0.5 . A cautious strategy is needed for orders in the supply line for the retailer as, the value of $\beta$ for the retailer is more than 0.5 . Further experiments were performed to investigate if the recommended policy was robust for all random values in the range of [0-15] and deterministic lead times. 50 sets of random customer's demand was generated by MATLAB, and the SBO was run 15 times for 
each set to determine the fitness function. The lowest fitness function found would be the optimal solution for that specific set of random values when all 50 sets of random values are examined. The results indicate that the aggressive approach to inventory gap for the manufacturer and retailer and cautious approach to order quantity for the retailer was optimal in 45 sets. This shows that the recommended policy for inventory replenishment is an effective policy for diminishing the BWE, CFB, and SCTC when demand varies slightly [015], and the lead times are deterministic. The lower inventory levels held by the SC members after employing the SBO method leads to lower SCTC comparing the information sharing. The total cost of the supply chain after using the SBO method decreased by 24 percent. The SCTC reduced to $£ 8292.74$ from the total cost of $£ 10947.54$ in SD model with information sharing.

\section{TAKE IN FIGURE 12.}

\subsection{Experiment 3}

Experiment 3 extends the experiment 2 through considering the stochastic lead times in addition to the stochastic demand. The shipping lead time varies in the range of $[0,4]$ in each time period. Figure 13(a) illustrates the ordering quantities for each member of the supply chain before applying the SBO and information sharing. It demonstrates the amplifications occurring in the orders and the customer's orders cannot be easily tracked. The manufacturer placed order (MPO) is 2.7 times more than the highest orders could be placed by the end customer at week 12. Although amplifications occurred in the placed orders, the performance of the members in tracking the customer's demand is better than their performance in experiment 2. Therefore, the inventory levels of the members that are shown in Figure 13(b) are lower than the inventory levels in experiment 2.

In experiment 3 , before employing information sharing and SBO, the highest inventory level held by the SC members is 27 , which is held by the distributor at week 30 of the simulation. Whilst in experiment 2 the highest inventory level held by the SC members before employing the information sharing and SBO is 110 , which was held by the distributor at week 35 (see Figure 10(b)). Figure 13(c) depicts the oscillations in cash cycles of the members, which are lower than the cash cycle oscillations in experiment 2. The highest CCC for the SC members before information sharing and SBO in experiment 3 is 40 days. Whilst the highest CCC for the SC members before information sharing and SBO in experiment 2 is 1432 days. The accumulated cost of the supply chain in this experiment before applying BWE reduction techniques is $£ 18387.96$, which is higher than the total cost in experiment 2, notwithstanding the lower levels of the inventory held by the members. The reason is that uncertainty in lead times affects the on-time delivery of the products negatively and consequently stock outs increase. As the unit stock out cost is higher than the unit inventory holding cost, the total cost of the supply chain in experiment 3 is higher than the total cost in experiment 2.

\section{TAKE IN FIGURE 13.}

\subsubsection{Impact of information sharing}

The impact of information sharing on reducing the BWE, CFB, and SCTC is shown in Figure 14(a)-(c). The ordering quantity of all members is given in Figure 14(a), which has a scale of $0-23$. While before information sharing, the placed orders by the SC members has a scale 0 40 (see Figure 13(a)). Although the ability of the members in tracking the customer's demand 
is ameliorated as a result of information sharing, the inventory levels illustrated in Figure 14(b) show amplifications and are higher than the inventory levels before information sharing. The inventory levels of the SC members before information sharing has a scale of 027(see Figure 13(b)). While, after the information sharing the inventory levels of the SC entities vary in the range of $[0,42]$ (see Figure 14(b)). The higher inventory levels help the members to mitigate the lost sale, which decreases the total cost to $£ 10672.94$ after information sharing, from the original cost of $£ 18387.96$ before information sharing. Figure 14(c) depicts the CCC of the members after information sharing that have risen compared with before information sharing. The $\mathrm{CCC}$ increases are caused by higher days inventory outstanding that is caused by higher inventory levels. According to the results illustrated in Figure 13(c), the CCCs of the members before information sharing has a scale of 0-40. Although, after the information sharing the CCCs of the SC entities vary in the range of [0, 687] (see Figure 14(c)).

\section{TAKE IN FIGURE 14.}

\subsubsection{Impact of $S B O$}

Using the values for the GA parameters presented in experiment 1, the SBO is run 15 times. The standard deviation of the obtained fitness values is 8.59 and the best fitness value is 8761.54. The order quantities of the members are shown in Figure 15(a), and have a scale of $0-30$. Similar to experiment 2, the largest order placed by a member in the SBO method is higher than the largest order placed in the case of information sharing, i.e., 23 (see Figure 14(a)). Whilst the inventory levels of the members, are illustrated in Figure 15(b), are much lower than the inventory levels in the information-sharing scenario. In the SBO model, the inventory of the retailer who possess the highest inventory level among the SC members from week 60 until the end of the simulation remains at 8 crates. While, in the SD model with information sharing the inventory of the retailer who possess the lowest volatility among the SC members fluctuates in the range of $[0,42]$ at the same time period (see Figure $14(\mathrm{~b})$ ). The cash cycle of the members after using the SBO method is shown in Figure 15(c) that proves the cash flow bullwhip is significantly reduced comparing the SD model with information sharing. After employing the SBO method, the CCC of the retailer who possess the highest cash to cash cycle among the members remains at 10 days from week 60 until the end of the simulation. While, in the SD model with information sharing the CCC of the retailer has a scale of 0-275 (see Figure 14(c)).

\section{TAKE IN FIGURE 15.}

The SBO method proposes an aggressive approach to bridging the gap between the desired inventory and current net inventory for the distributor and the wholesaler. The value of $\alpha$ for the distributor and wholesaler is less than 0.5 , and a cautious strategy is required for orders in the supply line for the distributor and wholesaler, i.e., the value of $\beta$ for the retailer is more than 0.5 . Further experiments were performed to investigate if the recommended policy was robust for all random values in the range of [0-15] and random lead times in the range of [0-4]. 50 random sets representing customer's demand and lead times were generated, and the SBO was run 15 times for each set to determine the fitness function. The lowest fitness function found would be the optimal solution for that specific set of random values. To identify the most frequent policy for bridging the inventory gap and supply line consideration, the recommended policies for the random sets are examined. Table 5 shows 
the replenishment policies that occurred most frequently and the associated mean fitness values.

This experiment proves that the replenishment policy is found by the SBO method. Aggressive policies by the distributor and wholesaler for inventory gap and cautious policies by the distributor and wholesaler to supply line are not robust for every set of random customer orders and lead times within the defined ranges. However, these policies occur most frequently and provide the highest fitness value. The lower inventory levels held by the SC members after employing the SBO method leads to lower SCTC comparing the information sharing. The accumulated cost of the supply chain in the SBO method amounts to $£ 8729.90$ which is 18 percent lower than the accumulated cost in the SD model with information sharing.

\section{TAKE IN TABLE 5.}

\section{Concluding discussion}

Supply chain management seeks to match the supply of products with the demand of customers. To maintain responsiveness in the supply chain, in addition to the product flow, the supply of monetary flow is required to be matched with the demand of the agents. Heterogeneous distribution of cash between supply chain members known as the cash flow bullwhip (CFB) decreases the efficiency of the supply chain. To address the issue, this study presented a simulation-based optimization approach in which a system dynamics simulation model and a multi objective optimization model are integrated to minimize CFB through the supply chain network in addition to minimization of the BWE and SCTC which have been investigated (O'donnell et al. 2006; Hassanzadeh, Jafarian, and Amiri 2014; Goodarzi et al. 2017).

\subsection{Theoretical contribution}

Incorporating financial flow modelling into SC models results in identifying the optimal financial decisions in addition to the optimal operational decisions (Tangsucheeva and Prabhu 2013; Goodarzi et al. 2017). This paper makes three main contributions. Firstly, it extends previous supply chain research on the application of GAs on minimizing the BWE (Lu et al. 2012; Duggan 2008) through diminishing the destructive effects of the BWE in SC cash flow in addition to the product flow. Secondly, it incorporates the cash flow modelling into inventory planning models and recognises the optimal values to the financial decisions parameters, in addition to the inventory decisions. Thirdly, it incorporates CFB minimization as an objective function into an SBO model. The results show that the GA has the ability to find the optimal financial and inventory decisions parameters for each member of the SC to reduce the total cost, BWE, and CFB.

The initial model is developed as in (Aslam and $\mathrm{Ng} 2016$ ) to validate the approach by observing similar results and then extending the SBO model. The main objective of the proposed SBO model is to find the optimal values of desired inventory, desired supply line, forecasting parameter for inventory, forecasting parameter for supply line, sales price per unit, and unit cost for supply chain entities to make trade-offs between the SCTC, CFB, and BWE. Three experiments were developed to investigate the ability of the SBO model in identifying the optimal replenishment policy. The first experiment was the MIT beer distribution game, which employs deterministic demand and lead times. The SBO found the 
optimal replenishment policy to be non-aggressive approach to the inventory gap for all members, and a cautious approach to orders in the supply line for the retailer and distributor. The second experiment tested random demand and deterministic lead times. The SBO found the optimal replenishment policy to be an aggressive approach to the inventory gap for the retailer and manufacturer, and a cautious approach to orders in the supply line for the retailer. The third experiment extended the second experiment through considering random lead times in addition to the random customer demand. In this experiment, an aggressive approach to the inventory gap for the distributor and wholesaler and cautious approach to orders in supply line for the distributor and wholesaler was identified to be the optimal replenishment policy, However, the recommended policy may not be optimal for every set of random customer demand and lead times.

The SD methodology which has been frequently used for BG modelling lacks the capability of providing optimal values to the decision variables. By applying SD modelling, the modeller is solely able to compare the effects of varied policies, different values of the controllable parameters, through performing what-if analysis which may not be an effective strategy particularly, when the decision parameters are continuous. Consequently, incorporating optimization algorithms into the SD simulation transforms it to a prescriptive tool, rather than a descriptive one. The results demonstrated the superiority of the SBO approach over SD modelling with and without information sharing between supply chain members as it can manage the CFB within supply chain networks through deriving optimal values for the inventory, supply line, and financial decisions parameters in presence of conflicts between supply chain objectives.

\subsection{Managerial implications}

Working capital optimization in addition to the total cost optimization plays a pivotal role in boosting the efficiency of SCM. Therefore, it is imperative that working capital metrics such as the CCC are incorporated into supply chain models. The CCC represents the performance of a firm in managing its capital. The lower the CCC the more successful the firm is in managing its capital. High volatility in the CCCs of the SC members caused by the BWE yields volatility in liquidity that may trigger inefficiencies in operational processes of the members such as purchasing, and consequently reduce SC service levels. Given the results of our study, SC managers should control the fluctuations in the CCCs of the SC members, if they want to manage the liquidity within the SC network. The proposed SBO model in this research allows SC managers to mitigate the CFB significantly under deterministic and stochastic demand and lead time. This is achieved through identifying the optimal values for the sales price, unit cost, and inventory decisions of the members. In the original model of the $\mathrm{BG}$, the $\mathrm{CCC}$ for the SC members ranges from 30 to 500 days. After employing the SBO methodology, the $\mathrm{CCC}$ ranges from -15 to 32 days. In the presence of demand uncertainty in the BG model, the cash to cash cycle ranges from -5 to 1500 days. However, after employing the SBO methodology the CCC ranges from -5 to 40 days. In the presence of uncertainty in demand and lead times in the $\mathrm{BG}$ model, the $\mathrm{CCC}$ ranges from -5 to 40 days. After applying the SBO technique, the $\mathrm{CCC}$ ranges from -5 to 32 days.

As well as reducing the $\mathrm{CFB}$, the proposed SBO model shows how SC managers can reduce the SCTC significantly. In the original model of the BG, the SCTC amounted to $£ 10816$. However, after employing the SBO methodology the SCTC decreased to £7017.94. In the 
presence of demand uncertainty in the BG model, the SCTC amounted to $£ 14283.42$. Although, after employing the SBO methodology the SCTC reduced to $£ 8292.74$. In the presence of uncertainty in demand and lead times in the BG model, the SCTC amounted to $£ 18387.96$. While after applying the SBO technique, the SCTC diminished to $£ 8729.90$.

Moreover, the results of the conducted experiments show the superiority of the proposed SBO model over the information sharing strategy which is often implemented by SC managers in practice to mitigate the SCTC. After employing the SBO technique the SCTC reduced by $29 \%$ comparing the SCTC of the SD model with information sharing. Similarly, the SCTC in the SBO model under demand uncertainty and demand and lead time uncertainties reduced by $24 \%$ and $18 \%$, respectively comparing the SD model with information sharing. Reducing the gap between the SD model, with information sharing and the SBO model as the number of stochastic parameters increase, highlights the importance of information sharing among supply chain members in mitigating the SCTC. Therefore, SC managers who are managing SC networks which encounter various uncertainties could benefit from significant cost reduction through applying this information sharing strategy. 


\subsection{Limitations and future research}

To recognize directions for future research, the limitations of this work are as follows. Firstly, our simulation model was developed based on the beer distribution game structure (Sterman 1989; Joshi 2000). Similar simulation models can be developed to control cash flow bullwhip (CFB) for other supply chain networks. Secondly, in this paper, anchoring and adjustment heuristic (Tversky and Kahneman 1974) was employed as an inventory ordering policy. There are other replenishment policies such as reorder point-order quantity $(\mathrm{Q}, \mathrm{r})$ which may be integrated into future research. Thirdly, other BWE contributors such as order batch and lead time have not been optimized in this study. Another research opportunity may arise by extending this paper through considering the aforementioned parameters. Fourthly, further work can be carried out to identify an optimization algorithm which is more effective than the GA in CFB minimization under lead time uncertainty. Another research topic is to define other metrics rather than cash conversion cycle to measure cash flow bullwhip and controlling CFB through tuning its controllable parameters.

\section{References}

Adenso-Díaz, Belarmino, Plácido Moreno, Ester Gutiérrez, and Sebastián Lozano. 2012. “An Analysis of the Main Factors Affecting Bullwhip in Reverse Supply Chains." International Journal of Production Economics 135 (2). Elsevier: 917-28.

Aslam, Tehseen. 2013. "Analysis of Manufacturing Supply Chains Using System Dynamics and Multi-Objective Optimization." University of Skövde.

Aslam, Tehseen, and Amos H C Ng. 2016. "Combining System Dynamics and MultiObjective Optimization with Design Space Reduction.” Industrial Management \& Data Systems 116 (2). Emerald Group Publishing Limited: 291-321.

Bandaly, Dia, Ahmet Satir, and Latha Shanker. 2016. "Impact of Lead Time Variability in Supply Chain Risk Management." International Journal of Production Economics 180. Elsevier: 88-100.

Boulaksil, Youssef. 2016. "Safety Stock Placement in Supply Chains with Demand Forecast Updates." Operations Research Perspectives 3. Elsevier: 27-31.

Chatfield, Dean C. 2013. "Underestimating the Bullwhip Effect: A Simulation Study of the Decomposability Assumption." International Journal of Production Research 51 (1). Taylor \& Francis: 230-44.

Chen, Frank, Zvi Drezner, Jennifer K Ryan, and David Simchi-Levi. 2000. "Quantifying the Bullwhip Effect in a Simple Supply Chain: The Impact of Forecasting, Lead Times, and Information." Management Science 46 (3). INFORMS: 436-43.

Coppini, Matteo, Chiara Rossignoli, Tommaso Rossi, and Fernanda Strozzi. 2010. "Bullwhip Effect and Inventory Oscillations Analysis Using the Beer Game Model." International Journal of Production Research 48 (13). Taylor \& Francis: 3943-56.

Darwin, C. 1859. "On the Origin of Species, London: John Murray."

Diaz, Rafael, Mike P Bailey, and Sameer Kumar. 2016. "Analyzing a Lost-Sale Stochastic Inventory Model with Markov-Modulated Demands: A Simulation-Based Optimization Study." Journal of Manufacturing Systems 38. Elsevier: 1-12. 
Ding, Hongwei, Lyes Benyoucef, and Xiaolan Xie. 2009. "Stochastic Multi-Objective Production-Distribution Network Design Using Simulation-Based Optimization." International Journal of Production Research 47 (2). Taylor \& Francis: 479-505.

Disney, Stephen M, Ingrid Farasyn, Marc R Lambrecht, Denis R Towill, and Wim Van De Velde. 2007. "Controlling Bullwhip and Inventory Variability with the Golden Smoothing Rule.” European Journal of Industrial Engineering 1 (3). Inderscience Publishers: 241-65.

Dolgui, Alexandre, Dmitry Ivanov, and Maxim Rozhkov. 2019. "Does the Ripple Effect Influence the Bullwhip Effect? An Integrated Analysis of Structural and Operational Dynamics in the Supply Chain." International Journal of Production Research. Taylor \& Francis, 1-17.

Dominguez, Roberto, Salvatore Cannella, and Jose M Framinan. 2015. "The Impact of the Supply Chain Structure on Bullwhip Effect." Applied Mathematical Modelling 39 (2324). Elsevier: 7309-25.

Dudas, Catarina, Philip Hedenstierna, and Amos H C Ng. 2011. "Simulation-Based Innovization for Manufacturing Systems Analysis Using Data Mining and Visual Analytics." In The 4th Swedish Production Symposium 3-5 May 2011, Lund, 374-82.

Duggan, Jim. 2008. "Using System Dynamics and Multiple Objective Optimization to Support Policy Analysis for Complex Systems.” In Complex Decision Making, 59-81. Springer.

Forrester, Jay Wright. 1997. "Industrial Dynamics." Journal of the Operational Research Society 48 (10). Springer: 1037-41.

Gangopadhyay, Aryya, and Zhensen Huang. 2002. "Bullwhip Simulator: A System for Studying How Information Sharing Can Improve Supply Chain Management." In 33rd Annual Meeting of the Decision Sciences Institute, 6.

Gao, Jingmei, and Dingwei Wang. 2008. "Simulation-Based Optimization Method for ThreeEchelon Network Inventory System of a Supply Chain.” In Control and Decision Conference, 2008. CCDC 2008. Chinese, 2406-10. IEEE.

Geary, S, Stephen M Disney, and Dennis R Towill. 2006. "On Bullwhip in Supply Chainshistorical Review, Present Practice and Expected Future Impact." International Journal of Production Economics 101 (1). Elsevier: 2-18.

Georgiadis, Patroklos, and Efstratios Athanasiou. 2013. "Flexible Long-Term Capacity Planning in Closed-Loop Supply Chains with Remanufacturing." European Journal of Operational Research 225 (1). Elsevier: 44-58.

Goodarzi, Marziye, Payam Makvandi, Reza Farzipoor Saen, and Mohammad Daniel Sagheb. 2017. "What Are Causes of Cash Flow Bullwhip Effect in Centralized and Decentralized Supply Chains?" Applied Mathematical Modelling 44: 640-54. https://doi.org/10.1016/j.apm.2017.02.012.

Govindan, Kannan, A Jafarian, R Khodaverdi, and K Devika. 2014. “Two-Echelon MultipleVehicle Location-routing Problem with Time Windows for Optimization of Sustainable Supply Chain Network of Perishable Food." International Journal of Production Economics 152. Elsevier: 9-28.

Hamta, Nima, M Akbarpour Shirazi, S M T Fatemi Ghomi, and Sara Behdad. 2015. "Supply 
Chain Network Optimization Considering Assembly Line Balancing and Demand Uncertainty." International Journal of Production Research 53 (10). Taylor \& Francis: 2970-94.

Hassanzadeh, Amir, Ahmad Jafarian, and Maghsoud Amiri. 2014. "Modeling and Analysis of the Causes of Bullwhip Effect in Centralized and Decentralized Supply Chain Using Response Surface Method." Applied Mathematical Modelling 38 (9-10). Elsevier: 2353-65.

Hugos, Michael. 2011. "Key Concepts of Supply Chain Management." Essentials of Supply Chain Management, Third Edition. Wiley Online Library, 1-38.

Ivanov, Dmitry. 2017. "Simulation-Based Ripple Effect Modelling in the Supply Chain." International Journal of Production Research 55 (7). Taylor \& Francis: 2083-2101.

Ivanov, Dmitry. 2018. "Revealing Interfaces of Supply Chain Resilience and Sustainability: A Simulation Study." International Journal of Production Research 56 (10). Taylor \& Francis: $3507-23$.

Ivanov, Dmitry. 2019. “"A Blessing in Disguise'or 'as If It Wasn't Hard Enough Already': Reciprocal and Aggravate Vulnerabilities in the Supply Chain." International Journal of Production Research. Taylor \& Francis, 1-11.

Joshi, Yogesh Vijay. 2000. "Information Visibility and Its Effect on Supply Chain Dynamics." Massachusetts Institute of Technology.

Keramati, Amir. 2010. "Supply Chain Integration: A Modelling Classification.” In Eighth Annual International Symposium on Supply Chain Management.

Keramydas, Christos, Ioannis Mallidis, Rommert Dekker, Dimitrios Vlachos, and Eleftherios Iakovou. 2017. "Cost and Environmental Trade-Offs in Supply Chain Network Design and Planning: The Merit of a Simulation-Based Approach." Journal of Simulation 11 (1). Springer: $20-29$.

Kim, Chang-Seop, James Tannock, Mike Byrne, Richard Farr, Bing Cao, and Mahendrawathi Er. 2004. "State of the Art Review Techniques to Model the Supply Chain in an Extended Enterprise." Operations Management Division, University of Nottingham. Citeseer.

Kimbrough, Steven O, Dong-Jun Wu, and Fang Zhong. 2002. "Computers Play the Beer Game: Can Artificial Agents Manage Supply Chains?” Decision Support Systems 33 (3). Elsevier: $323-33$.

Kleijnen, Jack P C. 2005. "Supply Chain Simulation Tools and Techniques: A Survey." International Journal of Simulation and Process Modelling 1 (1-2). Inderscience Publishers: 82-89.

Kumar, Sameer, Jessica Eidem, and Diana Noriega Perdomo. 2012. "Clash of the ECommerce Titans: A New Paradigm for Consumer Purchase Process Improvement." International Journal of Productivity and Performance Management 61 (7): 805-30. https://doi.org/10.1108/17410401211263872.

La Fuente, David De, and Jesus Lozano. 2007. "Application of Distributed Intelligence to Reduce the Bullwhip Effect." International Journal of Production Research 45 (8). Taylor \& Francis: 1815-33. 
Lee, HL, V Padmanabhan, and S Whang. 1997. "The Bullwhip Effect In Supply Chains." Sloan Management Review 38 (3): 93-102. https://doi.org/10.1016/j.ijpe.2008.08.035.

Lin, Wen-Jin, Zhi-Bin Jiang, Ran Liu, and Lei Wang. 2014. "The Bullwhip Effect in Hybrid Supply Chain.” International Journal of Production Research 52 (7). Taylor \& Francis: 2062-84.

Lu, J., P. Humphreys, R. McIvor, L. Maguire, and F. Wiengarten. 2012. "Applying Genetic Algorithms to Dampen the Impact of Price Fluctuations in a Supply Chain." International Journal of Production Research 50 (19): 5396-5414. https://doi.org/10.1080/00207543.2011.630041.

Ma, Junhai, and Xiaogang Ma. 2017. "Measure of the Bullwhip Effect Considering the Market Competition between Two Retailers." International Journal of Production Research 55 (2). Taylor \& Francis: 313-26.

Macdonald, John R, Christopher W Zobel, Steven A Melnyk, and Stanley E Griffis. 2018. "Supply Chain Risk and Resilience: Theory Building through Structured Experiments and Simulation." International Journal of Production Research 56 (12). Taylor \& Francis: 4337-55.

Mele, Fernando D, Gonzalo Guillen, Antonio Espuna, and Luis Puigjaner. 2006. “A Simulation-Based Optimization Framework for Parameter Optimization of SupplyChain Networks." Industrial \& Engineering Chemistry Research 45 (9). ACS Publications: 3133-48.

Mosekilde, Eric, Eric Larsen, and John D Sterman. 1991. "Coping with Complexity: Deterministic Chaos in Human Decisionmaking Behavior." Beyond Belief: Randomness, Prediction, and Explanation in Science. Boston, CRC Press, 199-229.

Mula, Josefa, Francisco Campuzano-Bolarin, Manuel Díaz-Madroñero, and Katerine M Carpio. 2013. "A System Dynamics Model for the Supply Chain Procurement Transport Problem: Comparing Spreadsheets, Fuzzy Programming and Simulation Approaches." International Journal of Production Research 51 (13). Taylor \& Francis: 4087-4104.

Nikolopoulou, Amalia, and Marianthi G Ierapetritou. 2012. "Hybrid Simulation Based Optimization Approach for Supply Chain Management." Computers \& Chemical Engineering 47. Elsevier: 183-93.

O’donnell, Tina, Liam Maguire, R McIvor, and P Humphreys. 2006. "Minimizing the Bullwhip Effect in a Supply Chain Using Genetic Algorithms." International Journal of Production Research 44 (8). Taylor \& Francis: 1523-43.

Peirleitner, Andreas J, Klaus Altendorfer, and Thomas Felberbauer. 2016. “A Simulation Approach for Multi-Stage Supply Chain Optimization to Analyze Real World Transportation Effects." In Winter Simulation Conference (WSC), 2016, 2272-83. IEEE.

Puigjaner, Luis, and José Miguel Laínez. 2008. "Capturing Dynamics in Integrated Supply Chain Management." Computers \& Chemical Engineering 32 (11). Elsevier: 25822605.

Randall, Wesley S., and M. Theodore Farris. 2009. "Supply Chain Financing: Using Cash-to-cash Variables to Strengthen the Supply Chain.” International Journal of Physical Distribution \& Logistics Management 39 (8): 669-89. https://doi.org/10.1108/09600030910996314. 
Sterman, John D. 1989. "Modeling Managerial Behavior: Misperceptions of Feedback in a Dynamic Decision Making Experiment.” Management Science 35 (3). INFORMS: 32139.

Sterman, John D. 2000. Business Dynamics: Systems Thinking and Modeling for a Complex World.

Stewart, Gordon. 1995. "Supply Chain Performance Benchmarking Study Reveals Keys to Supply Chain Excellence.” Logistics Information Management 8 (2): 38-44. https://doi.org/10.1108/09576059510085000.

Streichert, Felix. 2002. "Introduction to Evolutionary Algorithms." Paper to Be Presented Apr 4.

Sudarto, Sumarsono, Katsuhiko Takahashi, and Katsumi Morikawa. 2017. "Efficient Flexible Long-Term Capacity Planning for Optimal Sustainability Dimensions Performance of Reverse Logistics Social Responsibility: A System Dynamics Approach.” International Journal of Production Economics 184. Elsevier: 179-92.

Syberfeldt, Anna. 2009. “A Multi-Objective Evolutionary Approach to Simulation-Based Optimisation of Real-World Problems." De Montfort University.

Tangsucheeva, Rattachut, and Vittaldas Prabhu. 2013. "Modeling and Analysis of Cash-Flow Bullwhip in Supply Chain." In International Journal of Production Economics, 145:431-47. https://doi.org/10.1016/j.ijpe.2013.04.054.

Torabi, S Ali, and Elkafi Hassini. 2008. "An Interactive Possibilistic Programming Approach for Multiple Objective Supply Chain Master Planning.” Fuzzy Sets and Systems 159 (2). Elsevier: 193-214.

Tsai, Chih-Yang. 2017. "The Impact of Cost Structure on Supply Chain Cash Flow Risk." International Journal of Production Research 55 (22). Taylor \& Francis: 6624-37.

Tsai, Chih Yang. 2008. “On Supply Chain Cash Flow Risks.” Decision Support Systems 44 (4): 1031-42. https://doi.org/10.1016/j.dss.2007.12.006.

Tversky, Amos, and Daniel Kahneman. 1974. "Judgment under Uncertainty: Heuristics and Biases." Science 185 (4157). American association for the advancement of science: 1124-31.

Wan, Xiaotao, Joseph F Pekny, and Gintaras V Reklaitis. 2005. "Simulation-Based Optimization with Surrogate Models-Application to Supply Chain Management." Computers \& Chemical Engineering 29 (6). Elsevier: 1317-28.

Wangphanich, P, S Kara, and B Kayis. 2010. "Analysis of the Bullwhip Effect in MultiProduct, Multi-Stage Supply Chain Systems-a Simulation Approach.” International Journal of Production Research 48 (15). Taylor \& Francis: 4501-17.

Wu, Yue. 2006. "Robust Optimization Applied to Uncertain Production Loading Problems with Import Quota Limits under the Global Supply Chain Management Environment." International Journal of Production Research 44 (5). Taylor \& Francis: 849-82.

Yu, Zhenxin, Hong Yan, and T C Edwin Cheng. 2001. "Benefits of Information Sharing with Supply Chain Partnerships." Industrial Management \& Data Systems 101 (3). MCB UP Ltd: 114-21. 
Zaman, Tanzina, Sanjoy Kumar Paul, and Abdullahil Azeem. 2012. "Sustainable Operator Assignment in an Assembly Line Using Genetic Algorithm." International Journal of Production Research 50 (18). Taylor \& Francis: 5077-84.

Zhao, Fuguo, Desheng Dash Wu, Liang Liang, and Alexandre Dolgui. 2015. "Cash Flow Risk in Dual-Channel Supply Chain." International Journal of Production Research 53 (12). Taylor \& Francis: 3678-91. 
Fig. 2. A four-echelon supply chain

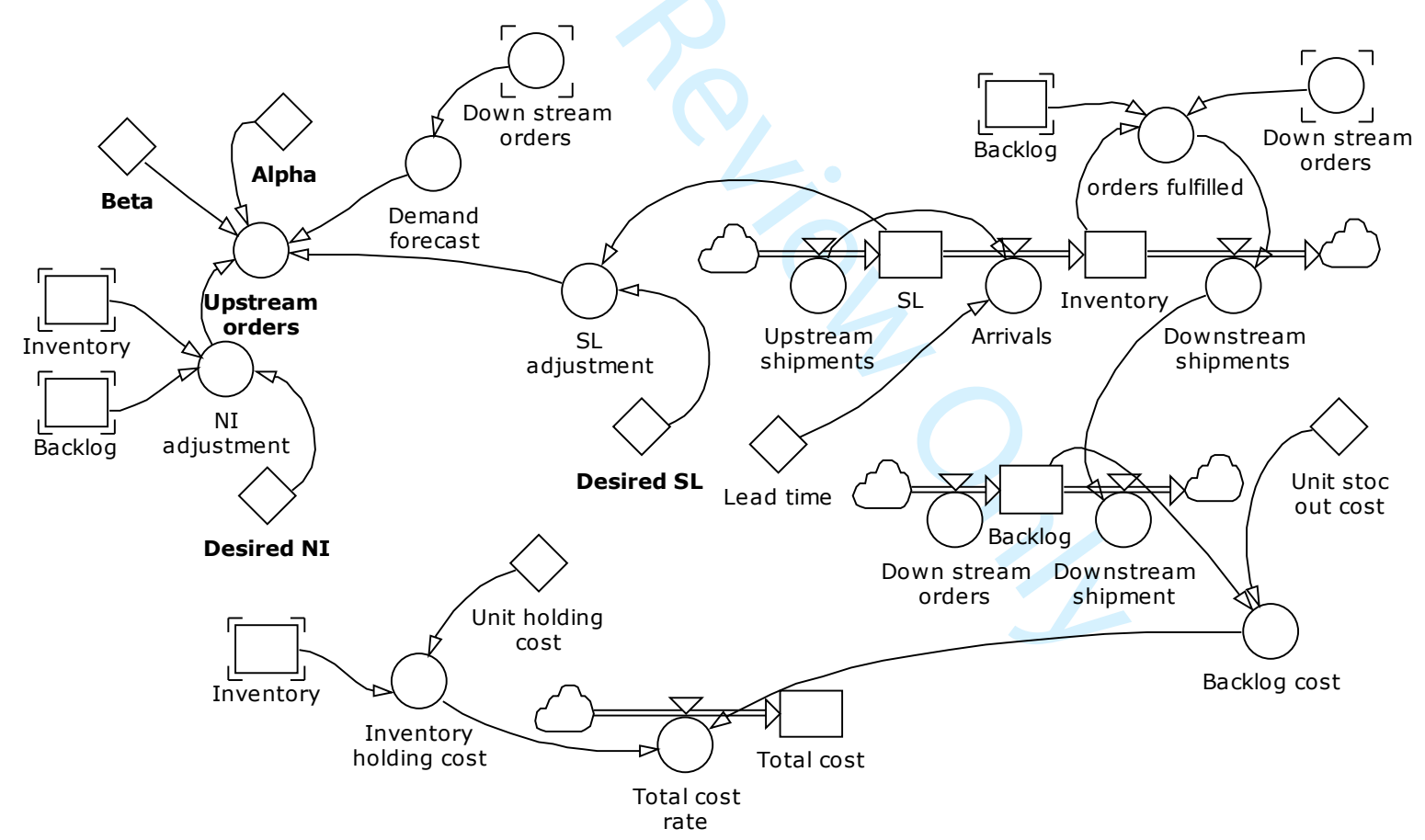

Fig. 3. Generic structure of material stock and flow diagram for a member 


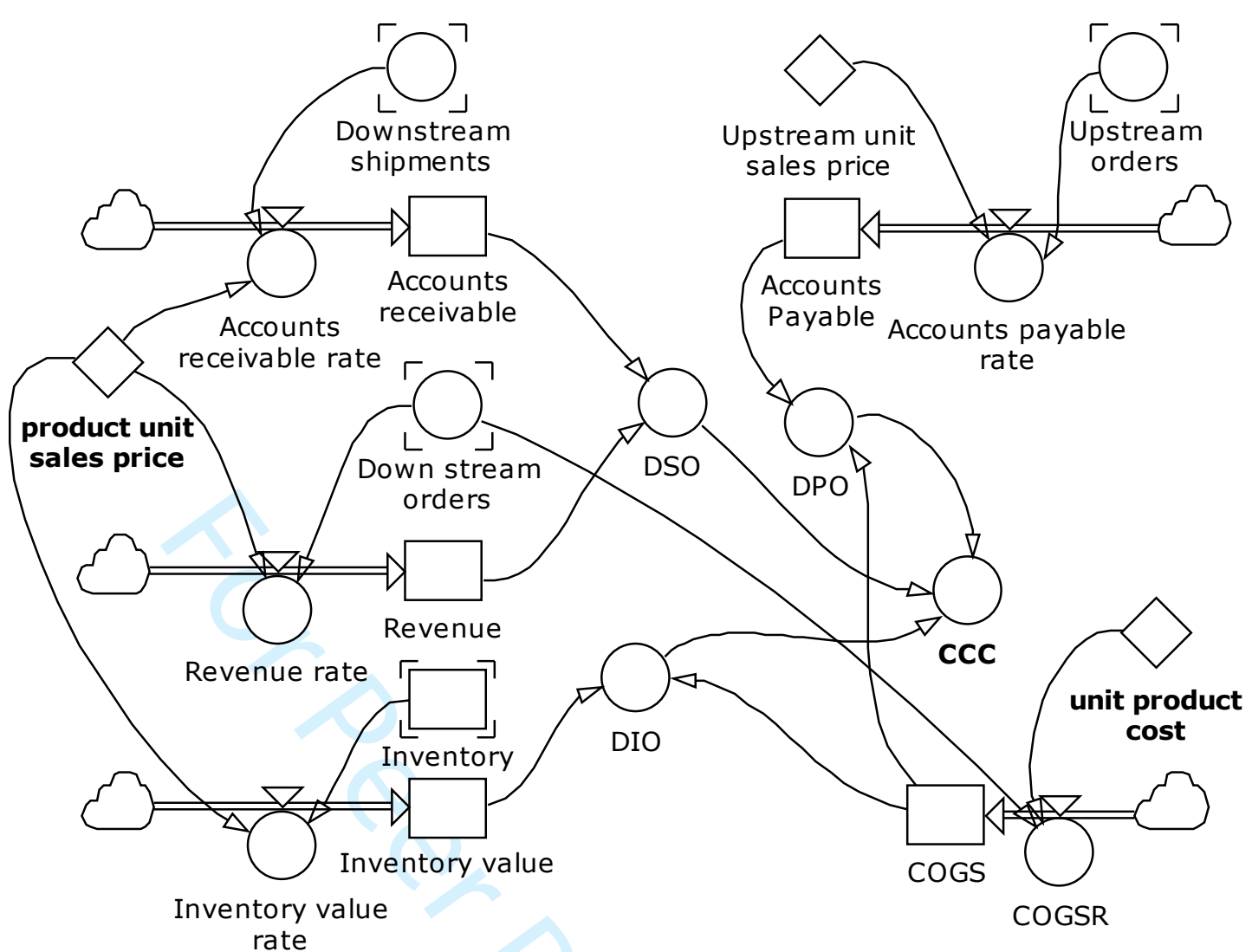

Fig. 4. Generic structure of financial stock and flow diagram for a member 

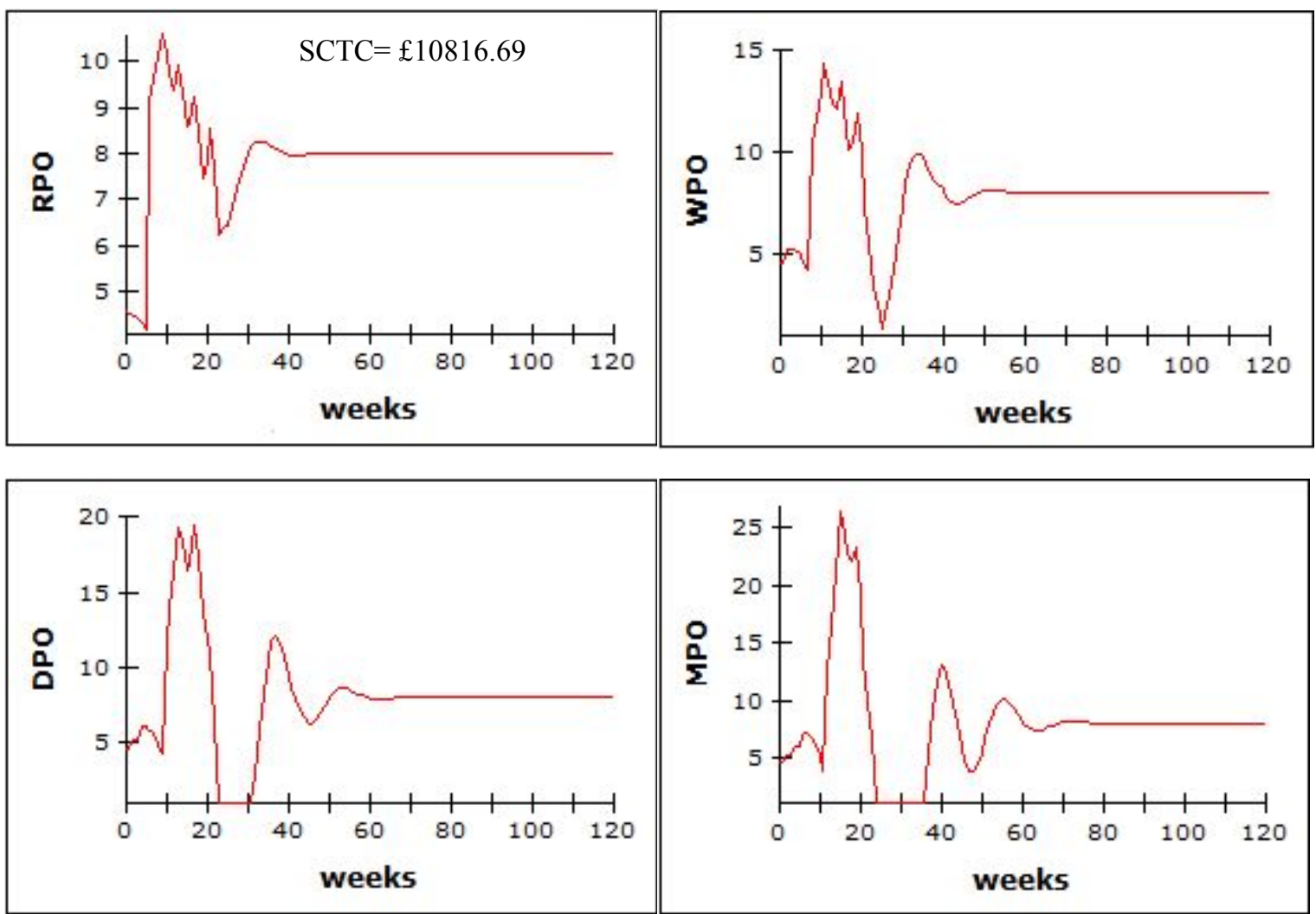

Retailer placed orders (RPO)

Wholesaler PO (WPO)

Distributor PO (DPO)

Retailer PO (RPO)

Figure 5. The bullwhip effect

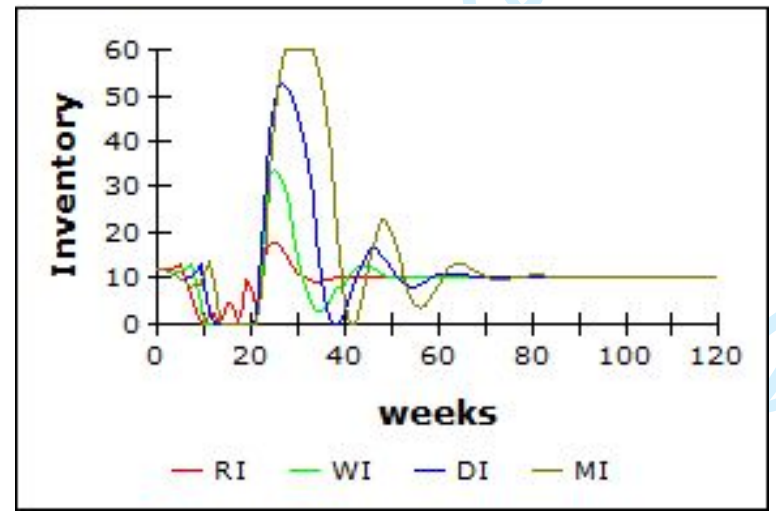

Figure 6. The inventory of supply chain members 

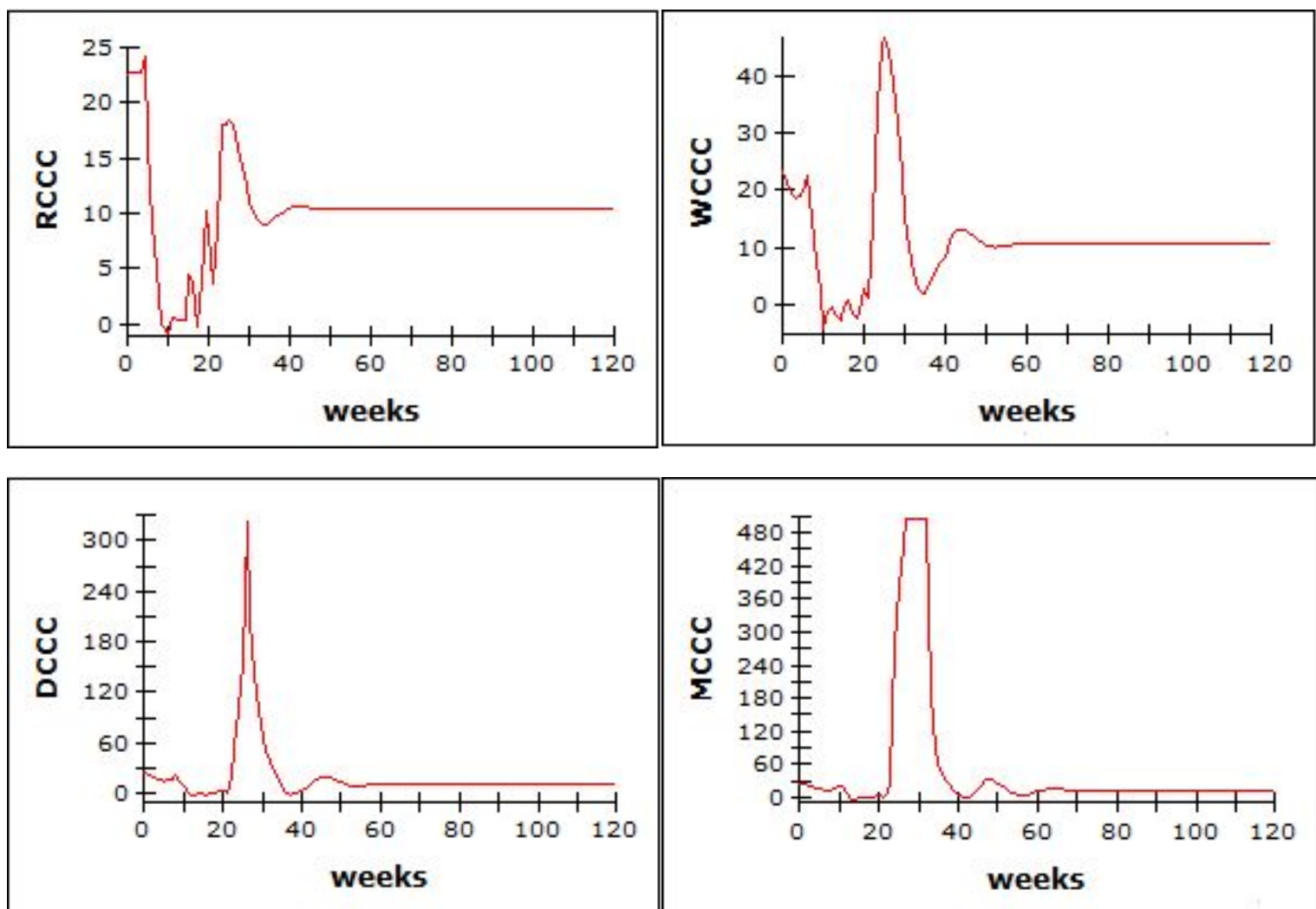

Retailer cash conversion cycle (RCCC)

Wholesaler CCC (WCCC)

Figure 2. The cash flow bullwhip

Distributor CCC (DCCC)

Retailer CCC (RCCC)
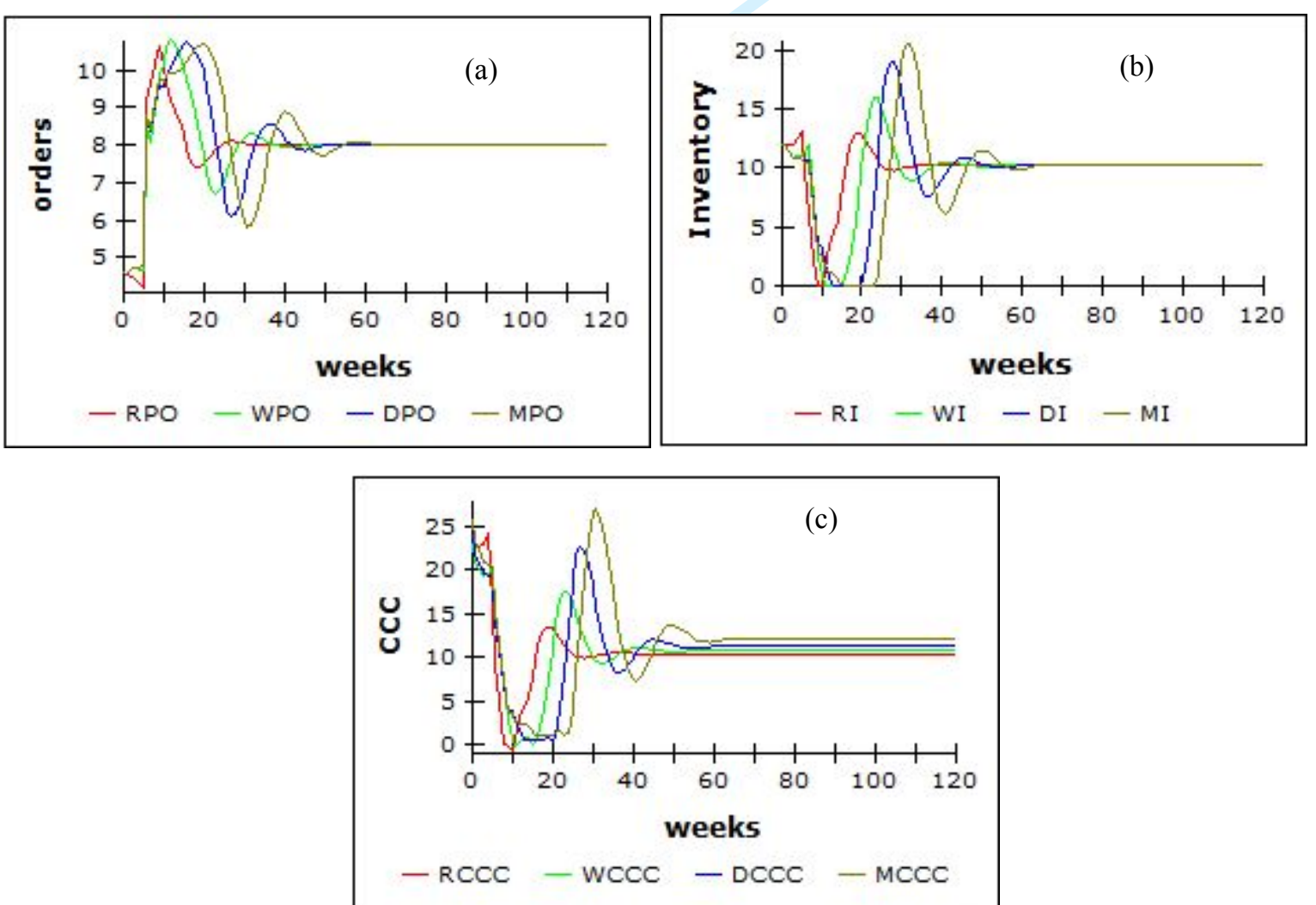

Figure 8. Impact of information sharing for experiment 1 

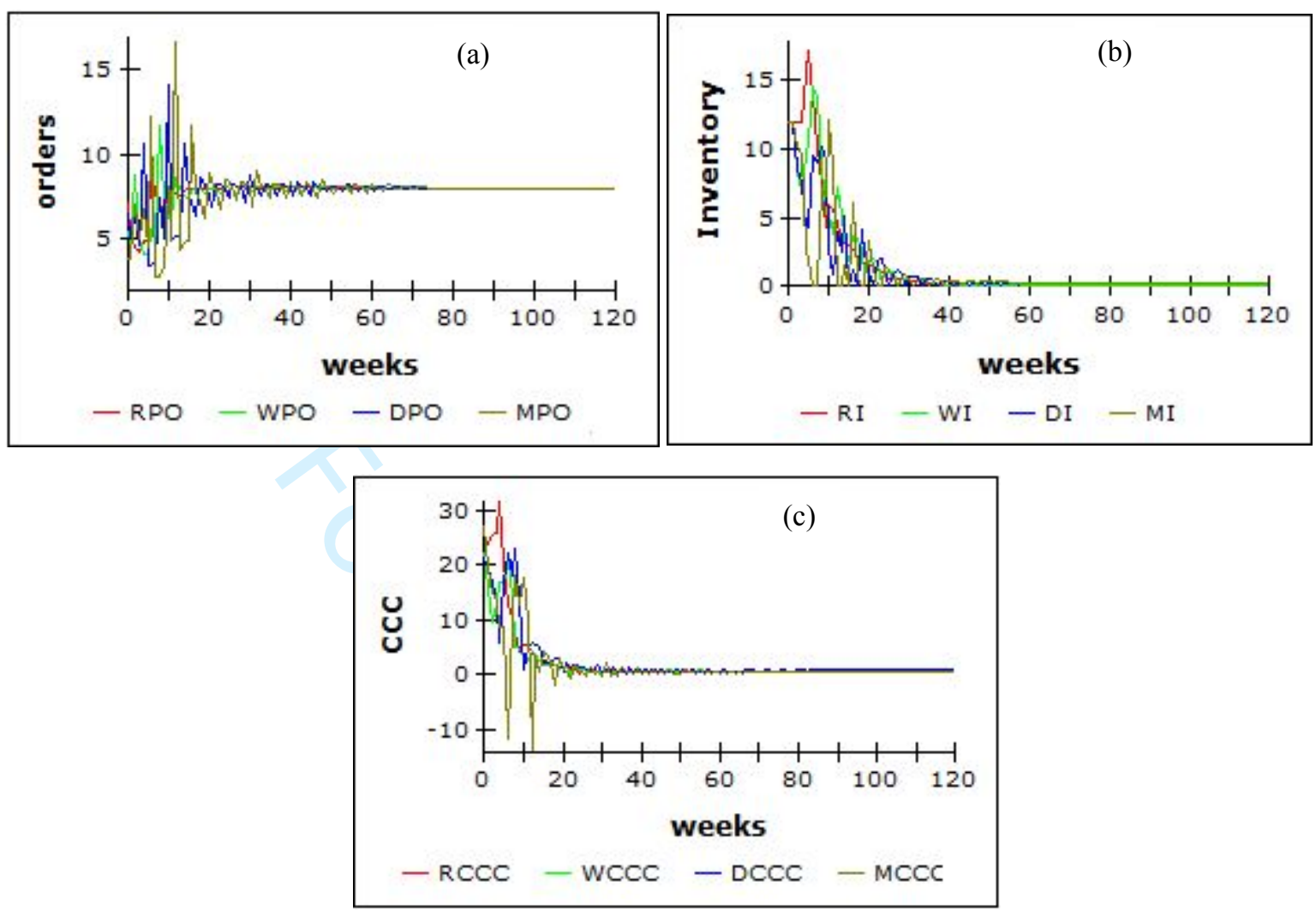

Figure 9. Impact of employing SBO for experiment 1
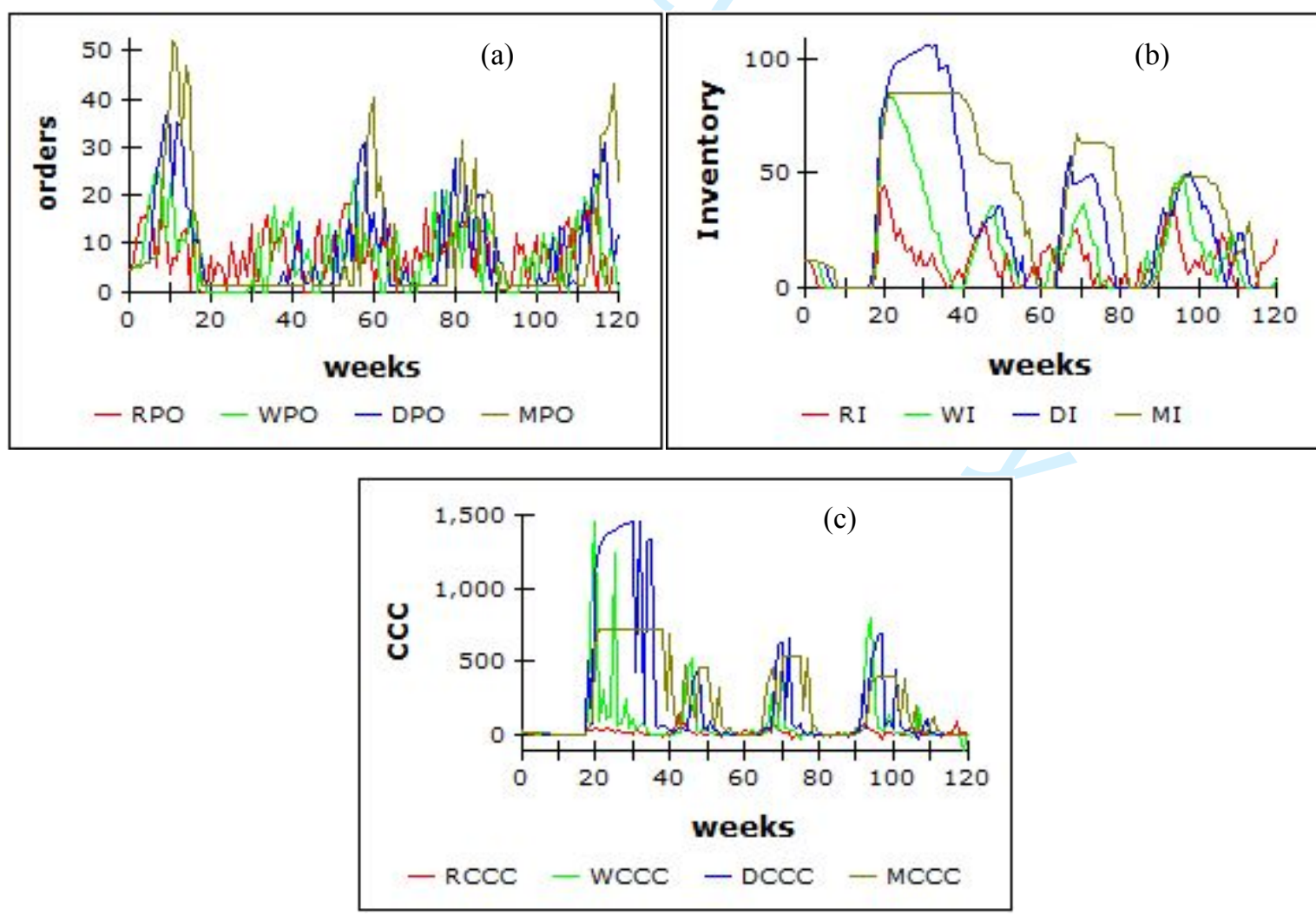

Figure 10. Results for experiment 2 before using information sharing and SBO 

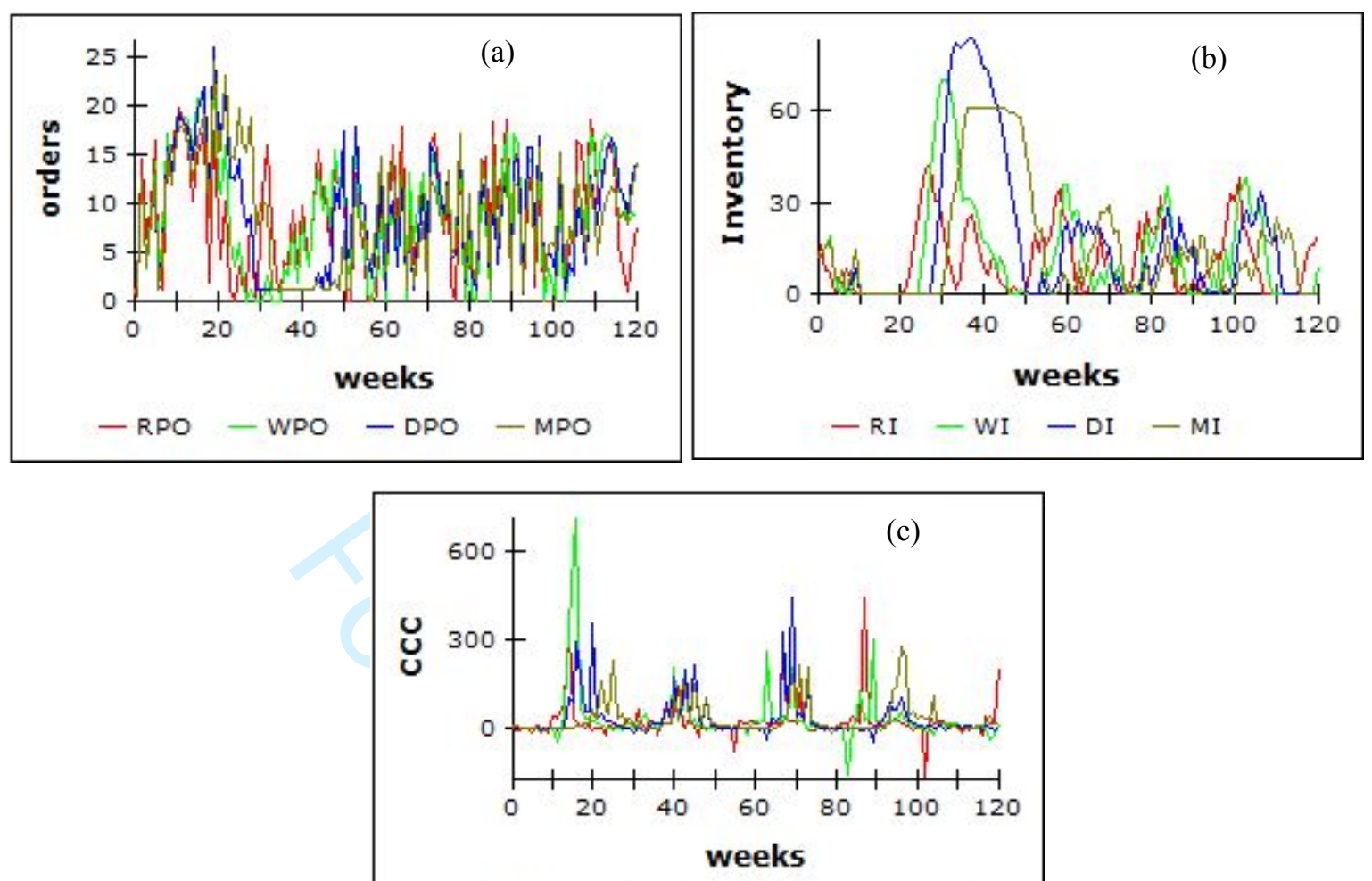

- RCCC - WCCC - DCCC - MCCC

Figure 11. Impact of information sharing for experiment 2
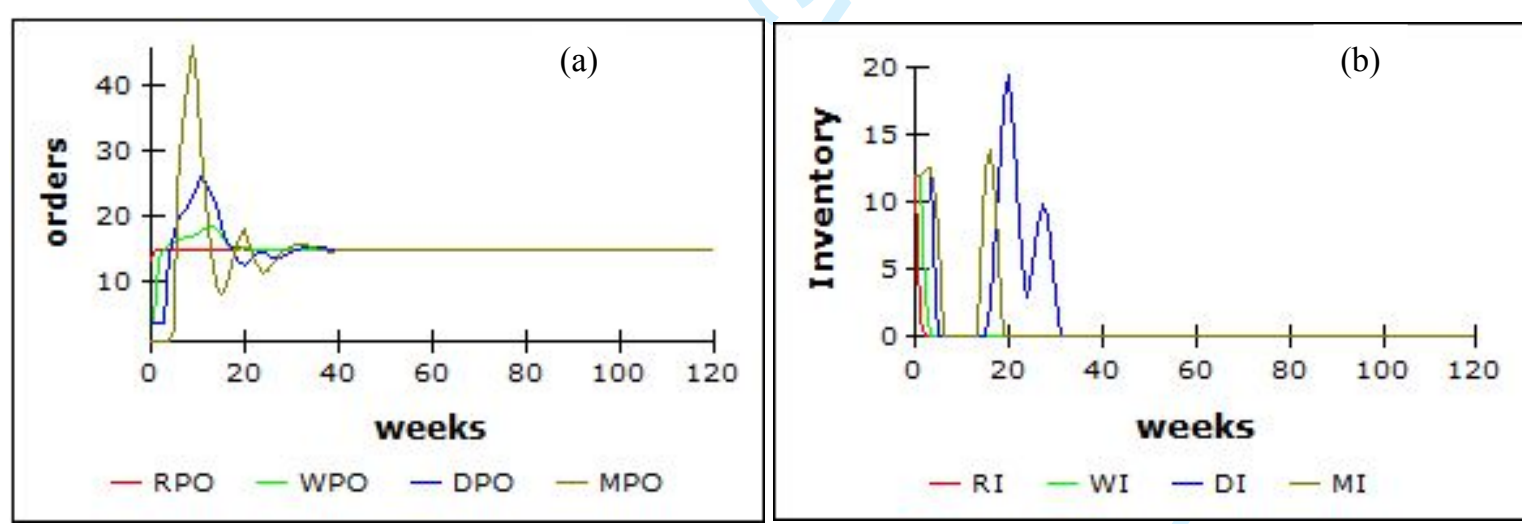

60

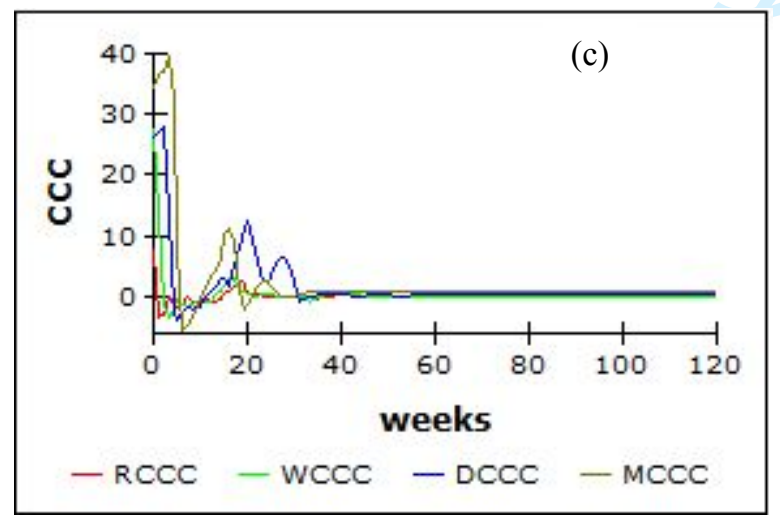

Figure 12. Impact of employing SBO for experiment 2 

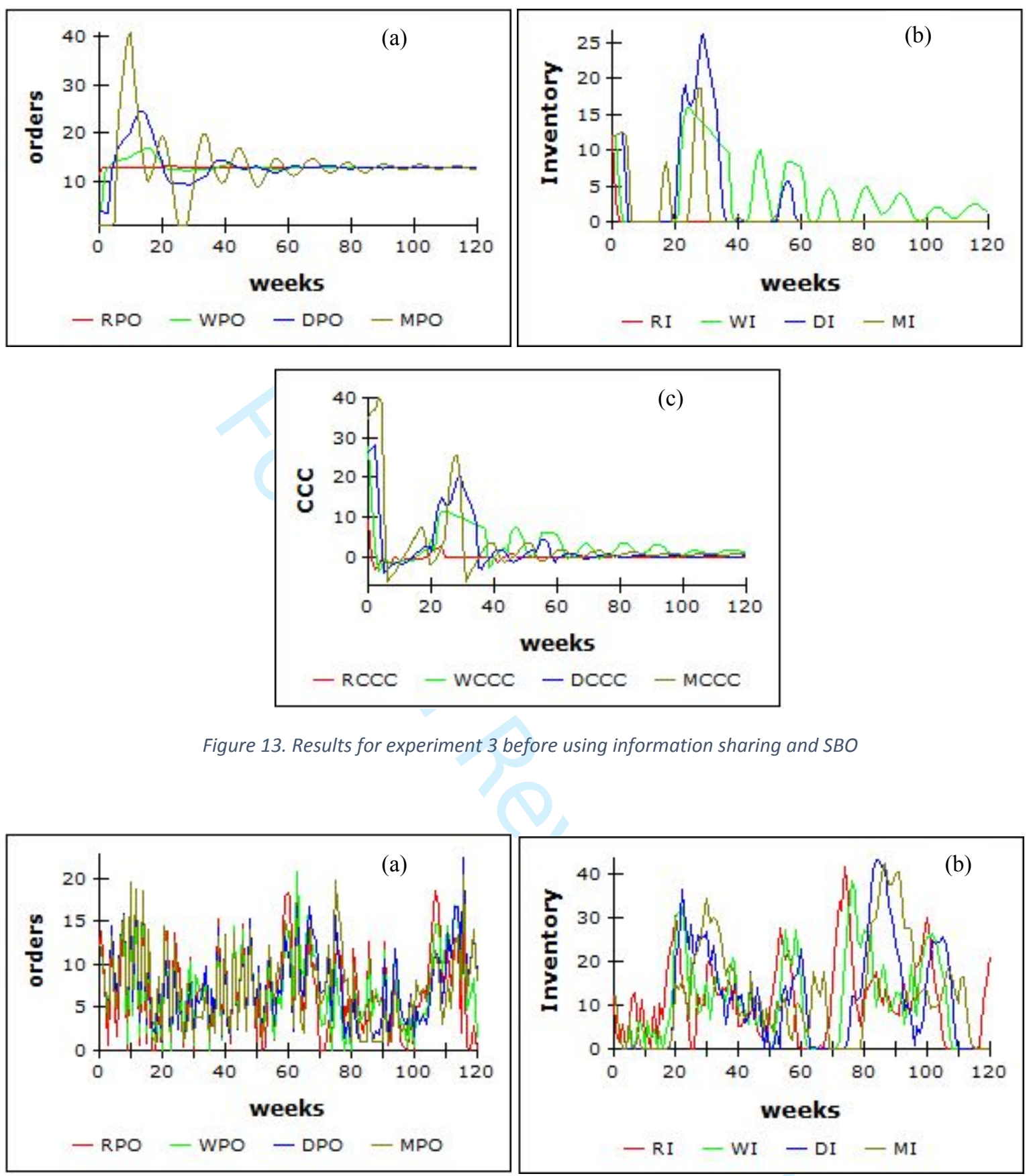

Figure 13. Results for experiment 3 before using information sharing and SBO

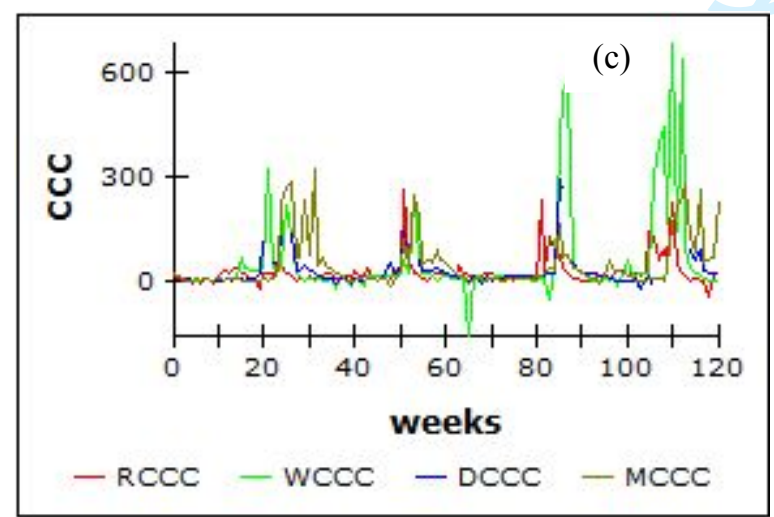

Figure 14. Impact of information sharing for experiment 3 

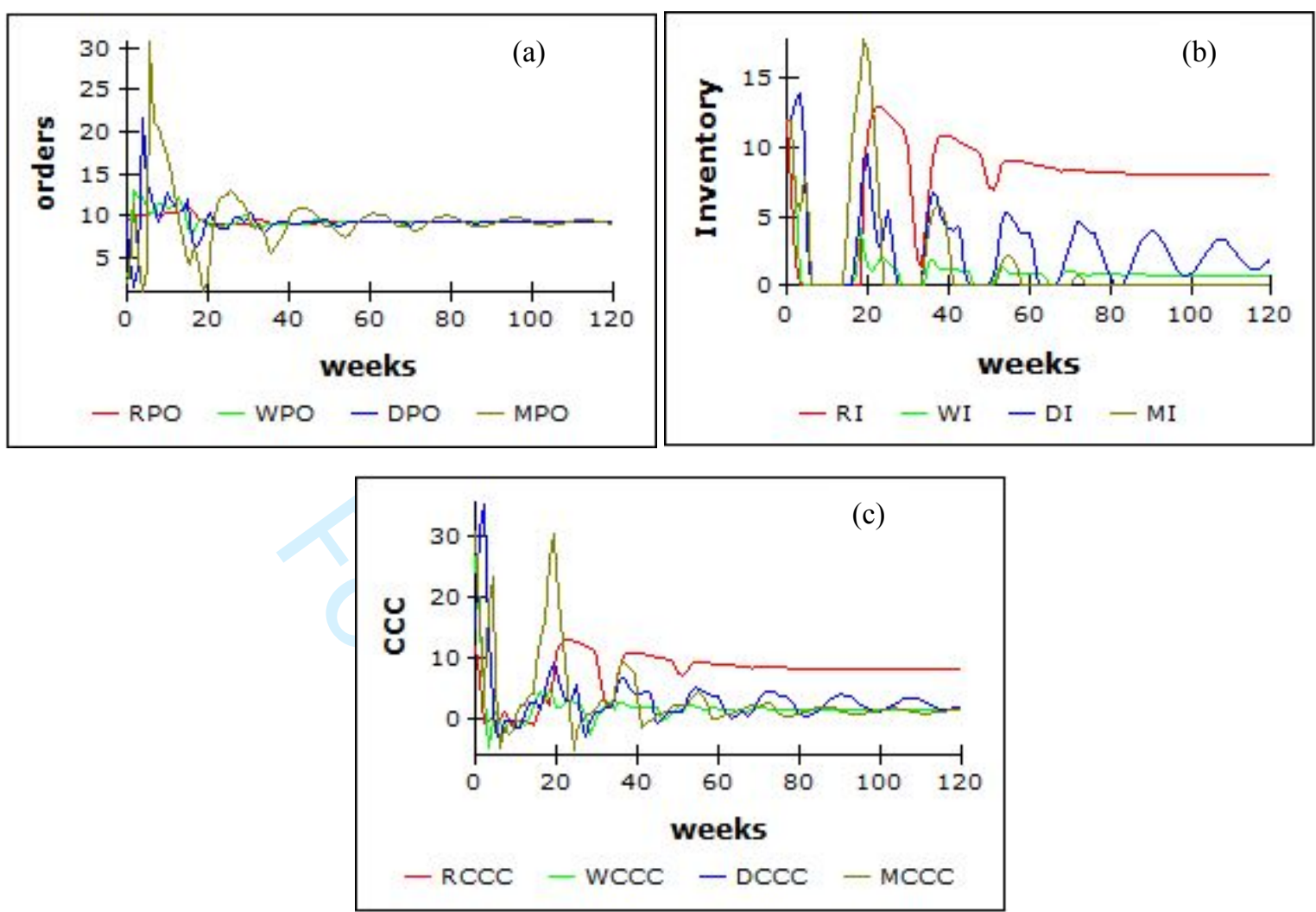

Figure 15. Impact of employing SBO for experiment 3 
Table 1. Review of the SBO modelling in supply chain

\begin{tabular}{|c|c|c|c|c|c|c|}
\hline $\begin{array}{l}\text { Authors } \\
\text { (years) }\end{array}$ & $\begin{array}{l}\text { Research } \\
\text { scope }\end{array}$ & $\begin{array}{l}\text { Optimization } \\
\text { technique }\end{array}$ & $\begin{array}{l}\text { Simulation } \\
\text { technique }\end{array}$ & $\begin{array}{l}\text { Optimization } \\
\text { objective }\end{array}$ & $\begin{array}{l}\text { Case } \\
\text { study }\end{array}$ & $\begin{array}{l}\text { Key decision } \\
\text { variables }\end{array}$ \\
\hline $\begin{array}{l}\text { (O'donnell } \\
\text { et al. 2006) }\end{array}$ & $\begin{array}{l}\text { SC inventory } \\
\text { planning }\end{array}$ & $\begin{array}{l}\text { Genetic } \\
\text { Algorithm } \\
\text { (GA) }\end{array}$ & $\begin{array}{l}\text { System } \\
\text { Dynamics } \\
\text { (SD) }\end{array}$ & $\begin{array}{l}\text { Min: Total } \\
\text { cost }\end{array}$ & $\begin{array}{l}\text { Beer } \\
\text { distributi } \\
\text { on game }\end{array}$ & $\begin{array}{l}\text { Order } \\
\text { quantities }\end{array}$ \\
\hline $\begin{array}{l}\text { (Georgiadis } \\
\text { and } \\
\text { Athanasiou } \\
\text { 2013) }\end{array}$ & $\begin{array}{l}\text { SC capacity } \\
\text { planning }\end{array}$ & $\begin{array}{l}\text { Proposed } \\
\text { MOO } \\
\text { methodology }\end{array}$ & SD & $\begin{array}{l}\text { Min: } \\
\text { sustainability } \\
\text { dimensions } \\
\text { performance } \\
\text { cost } \\
\text { Min: } \\
\text { remanufacturi } \\
\text { ng capacity } \\
\text { expansion }\end{array}$ & - & $\begin{array}{l}\text { Capacity } \\
\text { planning } \\
\text { decisions }\end{array}$ \\
\hline $\begin{array}{l}\text { (Aslam and } \\
\text { Ng 2016) }\end{array}$ & $\begin{array}{l}\text {. SC } \\
\text { Inventory } \\
\text { planning } \\
\text {. Bullwhip } \\
\text { effect }\end{array}$ & NSGA-II & $\mathrm{SD}$ & $\begin{array}{l}\text { Min: } \\
\text { Inventory } \\
\text { holding cost } \\
\text { Min: Backlog } \\
\text { cost } \\
\text { Min: } \\
\text { Bullwhip } \\
\text { effect }\end{array}$ & - & $\begin{array}{l}\text { Inventory } \\
\text { planning } \\
\text { decisions }\end{array}$ \\
\hline $\begin{array}{l}\text { (Sudarto, } \\
\text { Takahashi, } \\
\text { and } \\
\text { Morikawa } \\
\text { 2017) }\end{array}$ & $\begin{array}{l}\text { SC capacity } \\
\text { planning }\end{array}$ & $\begin{array}{l}\text { Proposed } \\
\text { MOO } \\
\text { methodology }\end{array}$ & $\mathrm{SD}$ & $\begin{array}{l}\text { Min: } \\
\text { sustainability } \\
\text { dimensions } \\
\text { performance } \\
\text { cost } \\
\text { Min: } \\
\text { remanufacturi } \\
\text { ng capacity } \\
\text { expansion }\end{array}$ & - & $\begin{array}{l}\text { Capacity } \\
\text { planning } \\
\text { decisions }\end{array}$ \\
\hline
\end{tabular}

\begin{tabular}{|l|l|l|l|l|l|l|}
\hline $\begin{array}{l}\text { Authors } \\
\text { (years) }\end{array}$ & $\begin{array}{l}\text { Research } \\
\text { scope }\end{array}$ & $\begin{array}{l}\text { Optimization } \\
\text { technique }\end{array}$ & $\begin{array}{l}\text { Simulation } \\
\text { technique }\end{array}$ & $\begin{array}{l}\text { Optimization } \\
\text { objective }\end{array}$ & $\begin{array}{l}\text { Case } \\
\text { study }\end{array}$ & $\begin{array}{l}\text { Key decision } \\
\text { variables }\end{array}$ \\
\hline $\begin{array}{l}\text { (Ding, } \\
\text { Benyoucef, } \\
\text { and Xie } \\
2009)\end{array}$ & $\begin{array}{l}\text {. SC network } \\
\text { design } \\
\text {. Distribution } \\
\text { planning } \\
\text { - Inventory } \\
\text { planning }\end{array}$ & $\begin{array}{l}\text { Non- } \\
\text { dominated } \\
\text { sorting } \\
\text { genetic } \\
\text { algorithm } \\
\text { (NSGA-II) }\end{array}$ & $\begin{array}{l}\text { Discrete } \\
\text { event } \\
\text { simulation } \\
\text { (DES) }\end{array}$ & $\begin{array}{l}\text { Min: Total } \\
\text { cost }\end{array}$ & $\begin{array}{l}\text { Automoti } \\
\text { ve } \\
\text { industry } \\
\text { Max: Service } \\
\text { level }\end{array}$ & $\begin{array}{l}\text {. Network } \\
\text { design } \\
\text { decisions } \\
\text {. Operation } \\
\text { strategies }\end{array}$ \\
\hline $\begin{array}{l}\text { (Bandaly, } \\
\text { Satir, and } \\
\text { Shanker } \\
\text { 2016) }\end{array}$ & $\begin{array}{l}\text { SC inventory } \\
\text { planning and } \\
\text { financial } \\
\text { hedging }\end{array}$ & GA & DES & $\begin{array}{l}\text { Min: Total } \\
\text { opportunity } \\
\text { cost }\end{array}$ & $\begin{array}{l}\text { Beer } \\
\text { industry }\end{array}$ & $\begin{array}{l}\text { - Quantity of } \\
\text { financial } \\
\text { options } \\
\text {. Safety stock } \\
\text { levels }\end{array}$ \\
\hline $\begin{array}{l}\text { (Keramydas } \\
\text { et al. 2017) }\end{array}$ & $\begin{array}{l}\text { SC network } \\
\text { design and } \\
\text { inventory } \\
\text { planning }\end{array}$ & OptQuest & DES & $\begin{array}{l}\text { Min: Total } \\
\text { cost } \\
\text { Min: CO2 } \\
\text { emissions }\end{array}$ & $\begin{array}{l}\text { White- } \\
\text { goods }\end{array}$ & $\begin{array}{l}\text {. Safety stock } \\
\text { levels } \\
\text {. The order } \\
\text { frequency } \\
\text {. Network } \\
\text { design }\end{array}$ \\
\hline
\end{tabular}




\begin{tabular}{|c|c|c|c|c|c|c|}
\hline $\begin{array}{l}\text { Authors } \\
\text { (years) }\end{array}$ & $\begin{array}{l}\text { Research } \\
\text { scope }\end{array}$ & $\begin{array}{l}\text { Optimization } \\
\text { technique }\end{array}$ & $\begin{array}{l}\text { Simulation } \\
\text { technique }\end{array}$ & $\begin{array}{l}\text { Optimization } \\
\text { objective }\end{array}$ & $\begin{array}{l}\text { Case } \\
\text { study }\end{array}$ & $\begin{array}{l}\text { Key decision } \\
\text { variables }\end{array}$ \\
\hline $\begin{array}{l}\text { (Mele et al. } \\
\text { 2006) }\end{array}$ & $\begin{array}{l}\text { SC inventory } \\
\text { planning }\end{array}$ & GA & $\begin{array}{l}\text { Agent-based } \\
\text { modelling }\end{array}$ & $\begin{array}{l}\text { Max: Total } \\
\text { profit }\end{array}$ & $\begin{array}{l}\text { Chemical } \\
\text { industry }\end{array}$ & $\begin{array}{l}\text { Inventory } \\
\text { parameters }\end{array}$ \\
\hline $\begin{array}{l}\text { (Nikolopoul } \\
\text { ou and } \\
\text { Ierapetritou } \\
\text { 2012) }\end{array}$ & $\begin{array}{l}\text { SC } \\
\text { production } \\
\text { scheduling } \\
\text {. Distribution } \\
\text { planning and } \\
\text { scheduling }\end{array}$ & MILP & $\begin{array}{l}\text { Agent-based } \\
\text { modelling }\end{array}$ & $\begin{array}{l}\text { Max: Total } \\
\text { cost }\end{array}$ & - & $\begin{array}{l}\text {. Production } \\
\text { planning } \\
\text { decisions } \\
\text {. Distribution } \\
\text { planning and } \\
\text { scheduling } \\
\text { decisions }\end{array}$ \\
\hline $\begin{array}{l}\text { (Peirleitner, } \\
\text { Altendorfer, } \\
\text { and } \\
\text { Felberbauer } \\
\text { 2016) }\end{array}$ & $\begin{array}{l}\text { SC inventory } \\
\text { planning }\end{array}$ & NSGA-II & $\begin{array}{l}\text { Agent-based } \\
\text { modelling }\end{array}$ & $\begin{array}{l}\text { Min: Total } \\
\text { cost } \\
\text { Max: Service } \\
\text { level }\end{array}$ & - & $\begin{array}{l}(\mathrm{s}, \mathrm{Q}) \\
\text { inventory } \\
\text { parameters }\end{array}$ \\
\hline
\end{tabular}

\begin{tabular}{|c|c|c|c|c|c|c|}
\hline $\begin{array}{l}\text { Authors } \\
\text { (years) }\end{array}$ & $\begin{array}{l}\text { Research } \\
\text { scope }\end{array}$ & $\begin{array}{l}\text { Optimization } \\
\text { technique }\end{array}$ & $\begin{array}{l}\text { Simulation } \\
\text { technique }\end{array}$ & $\begin{array}{l}\text { Optimization } \\
\text { objective }\end{array}$ & $\begin{array}{l}\text { Case } \\
\text { study }\end{array}$ & $\begin{array}{l}\text { Key decision } \\
\text { variables }\end{array}$ \\
\hline $\begin{array}{l}\text { (Puigjaner } \\
\text { and Laínez } \\
2008 \text { ) }\end{array}$ & $\begin{array}{l}\text {. SC network } \\
\text { design } \\
\text {. Distribution } \\
\text { planning } \\
\text {. Cash } \\
\text { management } \\
\text {. Bullwhip } \\
\text { effect }\end{array}$ & $\begin{array}{l}\text { Mixed integer } \\
\text { linear } \\
\text { programming } \\
\text { (MILP) }\end{array}$ & $\begin{array}{l}\text { Predictive } \\
\text { control }\end{array}$ & $\begin{array}{l}\text { Max: } \\
\text { Corporate } \\
\text { value }\end{array}$ & - & $\begin{array}{l}\text {. Financial } \\
\text { decisions } \\
\text {. Network } \\
\text { design } \\
\text { decisions } \\
\text {. Planning } \\
\text { decisions }\end{array}$ \\
\hline $\begin{array}{l}\text { (Gao and } \\
\text { Wang 2008) }\end{array}$ & $\begin{array}{l}\text { SC inventory } \\
\text { planning }\end{array}$ & $\begin{array}{l}\text { Particle } \\
\text { Swarm } \\
\text { optimization } \\
\text { (PSO) }\end{array}$ & NA & $\begin{array}{l}\text { Min: Total } \\
\text { cost }\end{array}$ & - & $\begin{array}{l}(\mathrm{r}, \mathrm{Q}) \\
\text { inventory } \\
\text { parameters }\end{array}$ \\
\hline $\begin{array}{l}\text { (Diaz, } \\
\text { Bailey, and } \\
\text { Kumar } \\
\text { 2016) }\end{array}$ & $\begin{array}{l}\text { SC } \\
\text { Inventory } \\
\text { planning }\end{array}$ & $\begin{array}{l}\text { Simulated } \\
\text { Annealing } \\
\text { Pattern } \\
\text { Search } \\
\text { Ranking and } \\
\text { Selection } \\
\text { (SAPS\&RS) }\end{array}$ & $\begin{array}{l}\text { Discrete } \\
\text { Markov- } \\
\text { modulated } \\
\text { Chain } \\
\text { (DMC) }\end{array}$ & $\begin{array}{l}\text { Min: Total } \\
\text { inventory cost }\end{array}$ & - & $\begin{array}{l}(\mathrm{s}, \mathrm{S}) \\
\text { inventory } \\
\text { parameters }\end{array}$ \\
\hline $\begin{array}{l}\text { (Boulaksil } \\
\text { 2016) }\end{array}$ & $\begin{array}{l}\text { SC inventory } \\
\text { planning }\end{array}$ & LP & NA & $\begin{array}{l}\text { Min: Total } \\
\text { cost } \\
\text { Max: Service } \\
\text { level }\end{array}$ & - & $\begin{array}{l}\text { Safety stock } \\
\text { levels }\end{array}$ \\
\hline
\end{tabular}


Table 2. Nomenclatures

\begin{tabular}{|c|c|}
\hline Symbol & Definition \\
\hline$O P_{t}$ & Ordering decision made at the end of period $\mathrm{t}$; \\
\hline$D F_{t}$ & Demand forecast at period $\mathrm{t}$ \\
\hline$N I_{t}$ & Net inventory at time t; \\
\hline$S L_{t}$ & Supply line at time t; \\
\hline$\gamma$ & Smoothing parameter; \\
\hline COGS & Cost of goods sold; \\
\hline DIO & Days inventory outstanding; \\
\hline DSO & Days sales outstanding; \\
\hline$D P O$ & Days payable outstanding; \\
\hline$q$ & Order quantity; \\
\hline$D$ & Demand; \\
\hline$I$ & Level of average inventory; \\
\hline$B$ & Backlog; \\
\hline$m$ & Collection policy; \\
\hline$n$ & Payment policy; \\
\hline$S C T C$ & Supply chain total cost; \\
\hline$M B W E$ & Manufacturer bullwhip effect; \\
\hline$M C F B$ & Manufacturer cash flow bullwhip; \\
\hline$T C_{i}$ & Total cost of entity $\mathrm{i}$ \\
\hline$M P O$ & Manufacturer placed orders; \\
\hline$M C C C$ & Manufacturer cash conversion cycle; \\
\hline$\sigma_{M P O}^{2}$ & Variance of manufacturer placed order; \\
\hline$\sigma_{\mathrm{DD}}^{2}$ & Variance of distributor demand; \\
\hline$\sigma_{M C C C}^{2}$ & Variance of manufacturer cash conversion cycle; \\
\hline$\alpha_{i}$ & $\begin{array}{l}\text { A fraction of the gap between desired on-hand inventory and current level of on-hand } \\
\text { inventory of entity } \mathrm{i} \text {; }\end{array}$ \\
\hline$\beta_{i}$ & $\begin{array}{l}\text { A fraction of the gap between desired supply line and current level of supply line of } \\
\text { entity } \mathrm{i} \text {; }\end{array}$ \\
\hline$D I_{i}$ & Desired inventory of entity $\mathrm{i}$; \\
\hline$D S L_{i}$ & Desired SL of entity i; \\
\hline$S P_{i}$ & Sales price per unit of entity $\mathrm{i}$; \\
\hline$U C_{i}$ & Unit cost of entity $\mathrm{i}$ \\
\hline$R P O$ & Retailer placed orders; \\
\hline$W P O$ & Wholesaler placed orders; \\
\hline$D P O$ & Distributor placed orders; \\
\hline$R I$ & Retailer inventory; \\
\hline$W I$ & Wholesaler inventory; \\
\hline$D I$ & Distributor inventory; \\
\hline$M I$ & Manufacturer inventory; \\
\hline$R C C C$ & Retailer cash conversion cycle; \\
\hline$W C C C$ & Wholesaler cash conversion cycle; \\
\hline$D C C C$ & Distributor cash conversion cycle; \\
\hline$i$ & Supply chain member index; \\
\hline
\end{tabular}

Table 3. Sales price and unit cost of supply chain members

\begin{tabular}{|c|c|c|c|c|c|c|c|}
\hline \multicolumn{2}{|l|}{ Manufacturer } & \multicolumn{2}{l|}{ Distributor } & \multicolumn{2}{l|}{ Wholesaler } & \multicolumn{2}{l|}{ Retailer } \\
\hline$S P$ & $U C$ & $S P$ & $U C$ & $S P$ & $U C$ & $S P$ & $U C$ \\
\hline 1.5 & 1.25 & 2 & 1.75 & 2.5 & 2.25 & 3 & 2.75 \\
\hline
\end{tabular}


Table 4. Impact of population size on fitness function

\begin{tabular}{|c|c|c|c|c|}
\hline \multirow{2}{*}{ Population size } & \multicolumn{4}{|l|}{ Reverse fitness value } \\
\cline { 2 - 5 } & Best (Min) & Worst (Max) & Mean & Standard deviation \\
\hline 50 & 7055.64 & 7116.68 & 7072.37 & 28.68 \\
\hline 100 & 7049.38 & 7136.38 & 7050.40 & 25.26 \\
\hline 150 & 7046.29 & 7073.51 & 7047.80 & 14.62 \\
\hline 200 & 7035.64 & 7053.38 & 7043.72 & 5.50 \\
\hline 250 & 7035.64 & 7052.23 & 7041.52 & 5.21 \\
\hline
\end{tabular}

Table 5. Replenishment policies found optimal for random demand and lead times

\begin{tabular}{|l|c|c|}
\hline Replenishment policy & Rate of occurrence & Mean reverse fitness value \\
\hline $\begin{array}{l}\text { Aggressive distributor and } \\
\text { wholesaler to net inventory gap } \\
\text { Cautious distributor and } \\
\text { wholesaler to supply line }\end{array}$ & 23 & 8876.28 \\
\hline $\begin{array}{l}\text { Aggressive manufacturer and } \\
\text { retailer to net inventory gap } \\
\text { Cautious retailer to orders in } \\
\text { supply line }\end{array}$ & 19 & 8935.61 \\
\hline $\begin{array}{l}\text { Non-aggressive members to } \\
\text { inventory gap } \\
\text { Cautious retailer and distributor }\end{array}$ & 8 & 9027.52 \\
\hline
\end{tabular}




\section{Appendix 1}

The detailed description of the financial stock and flow model are presented as follows. The accounts receivable for each agent (19) is the product of downstream shipments and unit sales price of the product. The sales price of each member's product is determined by (20)-(23).

The revenue of each agent (24) is defined as the product of unit sales price and downstream orders. The days sales outstanding (DSO) (25) is defined as average accounts receivable divided by the daily revenue. As the simulation model is run weekly, the revenue is divided by seven to determine daily revenue. To measure inventory value (26), the inventory level is multiplied by the product unit sales price. The cost of goods sold (COGS) (27) is measured by multiplying downstream orders and unit product cost. The unit product cost is composed of all the costs that the members incur for unit of product, such as the production cost for the manufacturer and purchasing cost for the distributor. The unit product cost for each member is defined by (28)-(31).

\begin{tabular}{|c|c|}
\hline$\underline{\mathrm{d}(\text { Accounts receivable })}=$ downstream shipments $\times$ prod & (19) \\
\hline $\mathrm{dt}=$ downstream shipments $\times$ product unit sales price & (19) \\
\hline Manufacturer unit sales price $=1.5$ & $(20)$ \\
\hline Distributor unit sales price $=2$ & $(21)$ \\
\hline Wholesaler unit sales price $=2.5$ & $(22)$ \\
\hline Retailer unit sales price $=3$ & $(23)$ \\
\hline$\frac{\mathrm{d}(\text { Revenue })}{\mathrm{dt}}=$ downstream orders $\times$ product unit sales price & $(24)$ \\
\hline DSO $=\frac{\text { Average(accounts receivable })}{\text { Revenue } / 7}$ & $(25)$ \\
\hline$\frac{\mathrm{d}(\text { Inventory value })}{\mathrm{dt}}=$ Inventory $\times$ product unit sales price & $(26)$ \\
\hline$\frac{\mathrm{d}(\mathrm{COGS})}{\mathrm{dt}}=$ downstream orders $\times$ unit product cost & $(27)$ \\
\hline Manufacturer unit product cost $=1.25$ & $(28)$ \\
\hline Distributor unit product cost $=1.75$ & $(29)$ \\
\hline Wholesaler unit product cost $=2.25$ & $(30)$ \\
\hline Retailer unit product cost $=2.75$ & (31) \\
\hline
\end{tabular}

The days inventory outstanding (DIO) (1) is measured by dividing the average inventory value into the daily COGS. To measure the amount of payables (33), product unit sales price of the upstream member is multiplied by orders. The days accounts payable outstanding (DPO) (34) is the ratio of average accounts payable and daily COGS. Cash 
conversion cycle (CCC) (35) for each supply chain member is the summation of DSO, and DIO minus DPO.

\begin{tabular}{|l|l|}
\hline $\mathrm{DIO}=\frac{\text { Average (inventory value) }}{\mathrm{COGS} / 7}$ & $(32)$ \\
\hline$\frac{\mathrm{d}(\text { Accounts payable })}{\mathrm{dt}}=$ orders $\times$ upstream unit sales price & $(33)$ \\
\hline $\mathrm{DPO}=\frac{\text { Average (accounts payable) }}{\mathrm{COGS} / 7}$ & $(34)$ \\
\hline $\mathrm{CCC}=\mathrm{DSO}+\mathrm{DIO}-\mathrm{DPO}$ & $(35)$ \\
\hline
\end{tabular}

